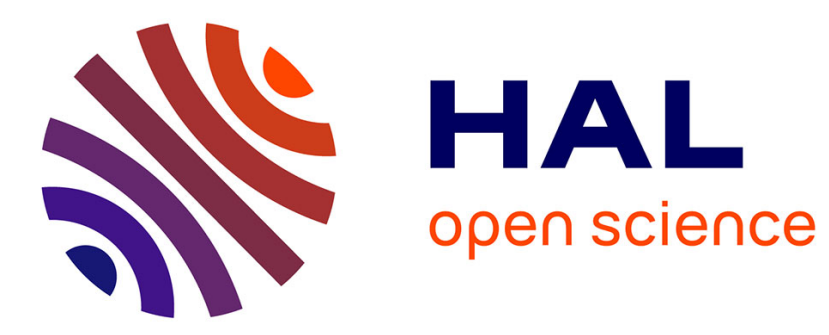

\title{
La liberté du sacrement Droit canonique et mariage des esclaves dans le Brésil colonial
}

Charlotte de Castelnau-L'Estoile

\section{To cite this version:}

Charlotte de Castelnau-L'Estoile. La liberté du sacrement Droit canonique et mariage des esclaves dans le Brésil colonial. Annales. Histoire, Sciences sociales, 2010, pp.1349-1383. halshs-02025491

\section{HAL Id: halshs-02025491 \\ https://shs.hal.science/halshs-02025491}

Submitted on 12 Jul 2019

HAL is a multi-disciplinary open access archive for the deposit and dissemination of scientific research documents, whether they are published or not. The documents may come from teaching and research institutions in France or abroad, or from public or private research centers.
L'archive ouverte pluridisciplinaire HAL, est destinée au dépôt et à la diffusion de documents scientifiques de niveau recherche, publiés ou non, émanant des établissements d'enseignement et de recherche français ou étrangers, des laboratoires publics ou privés. 


\title{
La liberté du sacrement Droit canonique et mariage des esclaves dans le Brésil colonial
}

\author{
Charlotte de Castelnau-L'Estoile
}

Les esclaves africains de Bahia, hommes et femmes, [Servi Aethiopes Bahiensis utriusq. sexus], se plaignent qu'ici ou là les maîtres leur interdisent de contracter mariage par des coups et des menaces et qu'ils sont forcés malgré eux au célibat. Cet abus n'a pas seulement envahi Bahia, mais s'est répandu dans tout le Brésil au grand détriment de leurs âmes. [...]

Cette difficulté majeure fait que ceux à qui par force on interdit le mariage se tournent tout naturellement vers des concubinages durables dans lesquels ils vieillissent misérablement même s'ils ont conçu de nombreux enfants. Certains [maîtres] interdisent à l'esclave de se marier avec une femme libre, dans ce but, ils allèguent qu'un esclave n'a pas besoin d'une femme et que les enfants nés de cette femme suivraient leur mère et seraient libres, ce que les [maîtres] supportent très difficilement. D'autres [maîtres] préferent avoir chez eux deux esclaves qui pendant des années vivent dans le péché, plutôt que de leur permettre de contracter librement des noces, pour la raison que, étant libres du lien du mariage, si l'occasion s'en présente, ils pourraient vendre l'un des deux en gardant l'autre.

Ils [Les esclaves] supplient intensément le très Saint Seigneur Pape qu'il venille tourner avec sollicitude les yeux sur ce malheureux petit troupeau, qu'il venille procurer un remède opportun à de telles souffrances. Il n'y aura pas de remède plus efficace qu'un rescrit envoyé au Brésil par sa Sainteté interdisant formellement qu'un maître puisse empêcher un esclave de contracter des noces légitimes en ajoutant une excommunication réservée à sa Sainteté dont la fulmination est le seul espoir pour effrayer les maîtres ${ }^{1}$.

1 - Rome, Archivio Storico della Sacra Congregazione de Propaganda Fide, désormais noté APF, vol. I (1649-1713), série Congressi, America Meridionale, doc. 164, fol. 467rv Le document 165 , fol. 468rv est une deuxième copie de la pétition. 
Dans ce Mémorial écrit en latin, les esclaves africains de Bahia exposent la violence des maîtres à laquelle ils sont confrontés quand ils souhaitent se marier. Ils demandent au pape une bulle d'excommunication apostolique contre les maitres qui ne respectent pas leur droit à contracter des noces légitimes. Ce document non daté est conservé aux archives de la Propaganda Fide avec une lettre écrite le 14 novembre 1708 depuis la ville de Bahia par un jésuite italien, Antonio De Brandolini, au secrétaire d'État de la Curie romaine ${ }^{2}$. Le jésuite, en transit au Brésil dans l'attente d'un bateau pour l'Inde, y explique que les maîtres empêchent les esclaves de se marier et qu'il transmet au pape un Mémorial écrit par une confrérie de noirs (confraternità dei Neri) de Salvador de Bahia.

Le Mémorial des esclaves est, par bien des aspects, surprenant. Des Africains, déportés au Brésil, des hommes et des femmes qui, par leur statut juridique d'esclaves, sont ramenés à l'état de marchandise, que l'on peut vendre, acheter, léguer, s'adressent directement au pape à Rome contournant les cadres du Padronado ecclésiastique de l'empire portugais pour demander que leur droit à contracter des noces légitimes soit respecté. Leur demande est formulée dans la langue et selon les règles du droit canonique. La lettre du père Brandolini désigne d'emblée l'existence d'un médiateur ecclésiastique dans cette demande des esclaves, mettant en garde contre toute lecture naïve. Il n'en demeure pas moins que le Mémorial, présenté comme ayant été écrit par les esclaves eux-mêmes, pose la question de la capacité d'action des esclaves, de leur aptitude à recourir au droit, en l'occurrence celui de l'Église, pour faire respecter leur statut de chrétiens, défendre leurs propres intérêts et se prémunir contre la violence de leurs maîtres ${ }^{3}$. Il invite aussi bien sûr à penser les rapports entre mariage et esclavage.

En ce début du XVIII ${ }^{\mathrm{e}}$ siècle, l'esclavage africain pénètre toute la société brésilienne ${ }^{4}$. Depuis la décennie 1690, la découverte d'or dans les régions intérieures provoque une demande croissante d'esclaves: plusieurs milliers d'Africains débarquent chaque année dans les ports du Brésil. Salvador de Bahia, capitale de

2 - APF, vol. I (1649-1713), série Congressi, America Meridionale, doc. 163, fol. 466rv-470rv. 3 - Les liens entre esclavage et droit constituent un axe central de l'historiographie actuelle sur l'esclavage. Pour le Brésil colonial, voir les travaux de Silvia Hunold Lara, Campos da violência. Escravos e senhores na capitania do Rio de Janeiro 1750-1808, Rio de Janeiro, Paz e Terra, 1988; Id., "Legislação sobre escravos africanos na América portuguesa ", in J. ANDrÉs-GALLEGo (dir.), Tres grandes cuestiones de la historia de Iberoamérica, Madrid, Fundación Mapfre Tavera/Fundación Ignacio Larramendí, 2005 ; Id., Fragmentos setecentistas. Escravidão, cultura e poder na América portuguesa, São Paulo, Companhia das Letras, 2007. Pour le cas français, l'historiographie est moins développée, voir le numéro de la revue Genèse, «Esclavage et Droit », 66-1, 2007.

4 - Pour le contexte de Bahia au début du XvIII ${ }^{\mathrm{e}}$ siècle, voir l'étude classique d'Antony J. R. Russell-Wood, Fildalgos and philanthropists: The Santa Casa da Misericordia of Bahia, 1550-1755, Berkeley, University of California Press, 1968, ainsi que les travaux de Stuart B. Schwartz, Sovereignty and society in colonial Brazil: The high court of Bahia and its judges 1609-1751, Berkeley, University of California Press, 1973; Id., "The manumission of slaves in colonial Brazil: Bahia, 1684-1745 ", The Hispanic American Historical Review, 54-4, 1974, p. 603-635; Id., Sugar plantations in the formation of Brazilian society: Bahia, 1550-1835, Cambridge/New York, Cambridge University Press, 1985. 
l'Amérique portugaise, siège de l'archevêché, compte 40000 habitants dont la moitié est esclave. En ville, les esclaves sont partout: domestiques, artisans, porteurs, prostituées, musiciens. Beaucoup de maîtres ne possèdent que quelques esclaves et presque toute la population libre en possède, même les libres de couleur. Dans la région rurale environnante, le recôncavo dédié à la culture de la canne à sucre et aux cultures vivrières, la population esclave dépasse les $60 \%$ et est regroupée dans des propriétés qui comptent des dizaines d'esclaves, parfois des centaines ${ }^{5}$. La chute du quilombo Palmares en 1697, refuge d'esclaves fugitifs qui avait su résister pendant tout le XVII ${ }^{\mathrm{e}}$ siècle aux assauts des armées hollandaise puis luso-brésilienne, marque un durcissement de la politique menée à l'égard des esclaves. La société coloniale de l'Amérique portugaise est de plus en plus nettement une société où l'esclavage constitue le pivot, économique, social et idéologique ${ }^{6}$.

Au début du XVIII ${ }^{\mathrm{e}}$ siècle, les esclaves africains de Bahia et le jésuite Brandoloni ne sont pas les seuls à se mobiliser en faveur du mariage légitime des esclaves. En 1707, l'archevêque de Salvador de Bahia a proclamé les premières Constitutions ecclésiastiques de l'Amérique portugaise. Sur les 1318 paragraphes des Constitutions de l'archevêché de Bahia, 38 concernent les esclaves et trois portent spécifiquement sur les questions du mariage et du concubinage des esclaves ${ }^{7}$. D'autres jésuites du Brésil, João Andreoni et Jorge Benci, figures importantes de la province, ont traité du même sujet. Ils dénoncent les pratiques seigneuriales visant à interdire le mariage des esclaves: Andreoni, sous le pseudonyme d'Antonil, dans son traité d'économie sur les richesses du Brésil écrit vers 1700 et Benci, dans ses sermons prononcés à la même époque à Salvador et publiés à Rome en $1705^{\circ}$. À travers la mise en série de ces documents, cet article s'attache à comprendre comment la question du mariage légitime des esclaves se posait au début du XVIII ${ }^{\mathrm{e}}$ siècle à la fois comme débat, comme enjeu et comme stratégie pour les différents acteurs

5 - Pour les chiffres de population, voir S. B. SCHWARTZ, «The manumission of slaves... », art. cit., p. 608.

6 - L'historiographie brésilienne sur l'esclavage a été considérablement renouvelée ces dernières années. Pour un bon aperçu en français, voir dans le dossier «Brésil colonial. Économie de la traite et résistance servile », Annales HSS, 61-2, 2006, les articles de João José REIS, «La révolte haoussa de Bahia en 1807. Résistance et contrôle des esclaves au Brésil», p. 383-418 et de Luiz Felipe de ALENCASTRO «Le versant brésilien de l'Atlantique Sud : 1550-1850 », p. 339-382; dans le dossier «Amériques coloniales. La construction de la société », Annales HSS, 62-3, 2007, l'article de Silvia HunOLd Lara, «Marronnage et pouvoir colonial. Palmares, Cucaú et les frontières de la liberté au Pernambouc à la fin du XVII ${ }^{\mathrm{e}}$ siècle", p. 639-662, ainsi que Jean Hébrard, Sidney Chalhoub et Silvia Hunold Lara (dir.), «L'esclavage au Brésil. Retour à l'archive: nouvelles approches de l'historiographie brésilienne ", Cahiers du Brésil contemporain, 65/66 et 67/68, 2007.

7 - Liv. I, «Sur les Sacrements », § $303 \& \S 304$ et liv. V, « Sur les délits et châtiments », $\S 989$ (dans la partie concernant les concubinages): Sebastião MonTEIRO DA VIDE, Constituições primeiras do Arcebispado da Bahia..., éd. par B. Feitler et E. S. Souza, São Paulo, Edusp, [1707] 2010.

8 - Jorge BENCI s.j., Economia cristã dos senhores no governo dos escravos, São Paulo, Éditoral Grijalbo, [1705] 1977; João A. ANDrEONI (João André ANTONIL), Cultura e opulência do Brasil por suas drogas e minas, trad. fr. et comm. par A. Mansuy, Paris, IHEAL, [1711] 1968. 
de la société esclavagiste brésilienne, pris chacun dans leur diversité : l'institution ecclésiastique, les maîtres d'esclaves et les esclaves.

Le mariage des esclaves est un point d'observation stratégique pour l'étude d'une société esclavagiste. Le mariage est la «clef de voûte de l'édifice social », pour reprendre une formule de Georges Duby à propos du mariage dans la société féodale 9 . Dans la société esclavagiste, le mariage des esclaves concerne tout l'édifice social. Non seulement à cause de la présence massive des esclaves, mais aussi parce que l'accès des esclaves au mariage pose des questions essentielles comme celles de leur appartenance au corps social, de leur statut juridique et de celui de leurs enfants. Le droit des esclaves à se marier se situe à la frontière entre la souveraineté que les maîtres exercent de droit sur leurs esclaves et l'autonomie des esclaves. L'ambiguïté fondamentale de l'esclavage moderne où l'esclave est à la fois une chose et une personne dotée d'une âme se manifeste clairement dans ces débats autour du mariage. L'affirmation par les autorités ecclésiastiques du droit des esclaves à se marier est aussi une affaire de représentation, d'image que cette société esclavagiste se fait d'elle-même et qu'elle veut donner aux autres. La question théorique du mariage des esclaves est donc centrale pour cette société esclavagiste qui se construit à la fois sur l'exclusion des esclaves et sur des formes négociées d'intégration.

Le combat de l'Église pour le mariage des esclaves nous plonge dans l'analyse du discours canonique et de ses liens avec les pratiques sociales. La victoire juridique de l'Église au Moyen Âge pour imposer sa logique du mariage n'a jamais signifié la disparition des formes concurrentes d'unions consensuelles entre les hommes et les femmes, qui comportaient elles aussi des formes de reconnaissance de la filiation et de solidarités matérielles. Dans les sociétés modernes, le discours dogmatique et juridique de l'Église continuait à se heurter à d'autres logiques, celle de l'État soucieux du respect des hiérarchies sociales, celle des familles désireuses de maintenir leur puissance, celle des individus épris de liberté. Les travaux des historiens montrent que les pratiques sociales étaient beaucoup plus souples que la seule étude des normes le laisse croire ${ }^{10}$. Concernant le mariage des esclaves, à côté de la logique de l'Église, il y avait celle des maîtres qui cherchaient à faire respecter leur droit de propriété et celle des esclaves qui espéraient améliorer leur sort. Ces logiques étaient différentes, elles pouvaient parfois converger ou au contraire s'opposer.

Les pratiques sociales autour du mariage des esclaves ne se réduisent pas à un débat normatif ni à des discussions canoniques qui n'en sont qu'un reflet, orienté dans le sens de la logique ecclésiastique. Cependant, les débats juridiques

9 - Georges Duby, Le chevalier, la femme et le prêtre. Le mariage dans la France féodale, Paris, Hachette, 1981, p. 23.

10 - Sur le lien entre pratiques sociales et vision ecclésiastique du mariage, et de manière générale, sur la richesse des archives ecclésiastiques pour une histoire du mariage dans les pays catholiques, voir les volumes dirigés par Silvana Seidel Menchi et Diego QuAGLIONI (dir.), I processi matrimoniali degli archivi ecclesiastici italiani, Bologne, Il Mulino, 2000-2004. 
ne sont pas cantonnés à des discussions internes à l'Église et la doctrine canonique du mariage des esclaves est utilisée par les différents acteurs de la société esclavagiste brésilienne. Les esclaves eux-mêmes y ont recours pour défendre leurs intérêts, comme le montre la pétition au pape de 1708 .

Après avoir souligné les enjeux et les tensions autour du mariage des esclaves dans cette société, on analysera les sens du combat de l'Église coloniale pour le mariage des esclaves, pour finir par une réflexion sur l'action des esclaves en faveur du mariage centrée sur l'étude du Mémorial de 1708.

\section{Mariage et relation esclavagiste dans le Brésil colonial}

Dans la société portugaise d'Ancien Régime, le mariage était une institution juridique qui produisait des effets de droit. Le mariage était l'union consensuelle d'un homme et d'une femme, une union monogame, indissoluble, impliquant une communauté de vie entre les époux, qui leur assurait une descendance légitime. Cette définition du mariage était une synthèse du droit romain et des exigences de la morale chrétienne, notamment l'indissolubilité ${ }^{11}$.

Or, dans le droit romain, le mariage des esclaves n'existait pas ${ }^{12}$. Il existait des unions inférieures (contubernium) entre esclaves, mais pas de "vrai mariage» (legitimum matrimonium), c'est-à-dire un mariage conforme au droit que seuls des «sujets de droit» pouvaient contracter. L'esclave n'étant pas reconnu comme une «personne» au sens juridique, il ne pouvait pas avoir une volonté reconnue par le droit. Le contubernium était donc une union servile simple, non reconnue par le droit. Les enfants issus de telles unions n'étaient pas rattachés au père, mais suivaient la condition de la mère et appartenaient au maître de celle-ci. Dans les sociétés de l'époque moderne, la logique juridique du mariage selon le droit romain et son exclusion aux esclaves gardaient une influence, notamment parce que le droit du ventre s'appliquait.

Le mariage avait bien sûr aussi une forte signification religieuse dans les sociétés catholiques d'Ancien Régime ${ }^{13}$. Il était considéré comme l'un des sept sacrements de l'Église, un acte solennel qui conférait la grâce divine et qui jouait un rôle essentiel dans l'économie du salut. Par le sacrement du mariage, l'union charnelle d'un homme et d'une femme prenait une signification religieuse, elle devenait une métaphore de l'union du Christ et de l'Église. Le sacrement du mariage, comme celui du baptême, était accessible à tous, libres ou esclaves. S'agissant du mariage des esclaves, la logique sacramentelle entrait d'emblée en contradiction avec la logique héritée du droit romain.

11 - Cette présentation du mariage s'appuie sur l'ouvrage de Jean GAUDEMET, Le mariage en Occident. Les mours et le droit, Paris, Éd. du Cerf, 1987.

12 - Ibid., p. 30-31.

13 - « Mariage en droit occidental », in R. NAZ (dir.), Dictionnaire de droit canonique, Paris, Letouzey et Ané, 1924, vol. VI, p. 740-787; Alfred VaCant et Eugène Mangenot, "Mariage ", Dictionnaire de théologie catholique, Paris, Letouzey et Ané, 1899-1968, t. IX-2, p. 2044-2335. 
Dans la société coloniale naissante du Brésil, la question du mariage des esclaves - à cette époque, principalement des esclaves indiens - se pose d'emblée comme un problème. Dès 1551, immédiatement après leur arrivée, les jésuites évoquent le refus par les maîtres de marier leurs esclaves:

Nous travaillons pour imposer une coutume sur cette terre, de marier les hommes et les femmes esclaves devant la Sainte Église. On en a marié beaucoup et l'on pourrait en marier plus si leurs maitres arrêtaient de croire qu'ils deviennent libres. Avec la venue de Monseigneur l'Évêque, nous espérons que beaucoup sera fait pour ce profit et que l'on remédiera à cela, car il y a beaucoup de propriétés qui ont de nombreux esclaves, hommes et femmes ${ }^{14}$.

Selon les jésuites, la crainte des maîtres selon laquelle le mariage libérerait de l'esclavage est infondée, car le droit canonique établit que les esclaves peuvent se marier et que le mariage ne les émancipe pas. Afin de clarifier le débat avant l'arrivée du premier évêque, le supérieur des jésuites, Manuel da Nóbrega, demande même le mois suivant une provision au roi du Portugal afin de préciser que les esclaves ne sont pas affranchis par le mariage ${ }^{15}$. La crainte des maîtres face au pouvoir libérateur du mariage est attestée dans tout le monde hispanique au $\mathrm{XVI}^{\mathrm{e}}$ siècle. Elle s'appuyait sur deux lois issues du corpus du droit royal médiéval (les Partidas qui datent $\mathrm{du} \mathrm{XIII}^{\mathrm{e}}$ siècle), qui avaient été sollicitées dans une provision de 1526 pour l'audience de Santo Domingo ${ }^{16}$. En fait, les conditions d'émancipation étaient très réduites, cependant cette possibilité suscita une grande inquiétude chez les maîtres ${ }^{17}$. À la suite de cette provision, la couronne espagnole s'attacha à nier le caractère émancipateur du mariage des esclaves à de nombreuses reprises, à la demande des autorités coloniales des différentes régions de l'Amérique ${ }^{18}$. La citation de Nóbrega permet de penser que, dans le cas du Brésil, régnait aussi cette incertitude.

Pour comprendre pourquoi le mariage des esclaves se pose toujours comme une difficulté, l'analyse structuraliste des sociétés esclavagistes par Moses Finley est éclairante ${ }^{19}$. L'esclave est une propriété dotée d'une âme, à la fois une chose et un être humain biologique. Pour résoudre ce paradoxe, les sociétés esclavagistes trouvent des procédures visant à dégrader et miner l'humanité de l'esclave pour le distinguer ainsi des êtres humains qui ne sont pas une propriété. Le mariage

14 - Lettre d'Antonio Pires aux frères de Coimbra, 2 août 1551, p. 259: Serafim LeITE, Monumenta Brasiliae, Rome, Monumenta Historica Societatis Jesu, 1956.

15 - Ibid., lettre de Manuel da Nóbrega à João III, roi du Portugal, 14 septembre 1551, § 7, p. 293.

16 - Daisy RíPoDAS ARdANAz, El matrimonio en Indias. Realidad social y regulación jurídica, Buenos Aires, Fundación para la Educación, la Ciencia y la Cultura, 1977, p. 250-257. 17 - Ibid., une des lois, partida IV, ley 1, titulo 5, précisait que les esclaves pouvaient se marier sans le consentement du maître et l'autre, partida IV, ley 8, titulo 22, stipulait qu'un esclave était libéré quand il se mariait avec une personne libre qui ignorait sa condition d'esclave, en présence de son maître si ce dernier taisait sa condition d'esclave. 18 - Ibid., en 1527, 1538, 1541 et 1553.

19 - Moses I. Finley, Esclavage antique et idéologie moderne, Paris, Éd. de Minuit, 1979. 
apparaît par bien des aspects comme une revendication d'humanité pour les esclaves et, par contrecoup, comme une mise en péril de la souveraineté domestique des maîtres, ce droit privé qu'ils possédaient sur leurs esclaves et qu'ils revendiquaient comme devant être sans limites ${ }^{20}$. Il est révélateur que les sources, notamment la pétition des esclaves de 1708 et le paragraphe 303 des Constitutions de l'archevêché de Bahia, évoquent les châtiments corporels que les maîtres imposaient à leurs esclaves désireux de se marier. Par l'usage du châtiment, les maîtres marquaient leur pouvoir sur leurs esclaves et leur rappelaient qu'ils n'étaient pas tout à fait des hommes, malgré les apparences et leurs aspirations. Analysé dans la perspective de la relation esclavagiste, le mariage des esclaves se situe dans un conflit de normes entre l'esclave comme chose soumise entièrement au pouvoir de son maître, et l'esclave comme personne qu'il est malgré tout. Les châtiments physiques seraient ainsi la réponse ordinaire des maîtres à ce qu'ils considèrent comme une atteinte à leur souveraineté domestique.

\section{Familles esclaves et mariage légitime dans le Brésil colonial}

Longtemps, l'historiographie a insisté sur l'absence de toute vie familiale des esclaves au Brésil et sur la faiblesse de la fécondité de la population servile. L'œuvre classique de Gilberto Freyre, Maîtres et esclaves, qui place la famille et la sexualité au cœur de la spécificité brésilienne, n'évoquait que les relations sexuelles entre les maîtres et les femmes esclaves mais pas la famille esclave ${ }^{21}$. Les historiens, analysant l'esclavage selon une logique économique, soulignaient qu'à cause de la forte offre de la traite en provenance d'Afrique, les maîtres ne recherchaient pas l'accroissement naturel de la population esclave et ne favorisaient pas les unions stables des esclaves. Le déséquilibre du sexe-ratio dans la population esclave des plantations en était la preuve éclatante. Les esclaves semblaient condamnés à des relations sexuelles furtives.

Sans contredire ce tableau général, les travaux récents accordent désormais une attention toujours plus grande à la famille esclave comme espace d'autonomie et d'adaptation pour les esclaves, mais aussi comme moyen de contrôle pour les maîtres. On peut même affirmer que l'histoire de la société esclavagiste brésilienne a été en partie repensée et reformulée depuis une vingtaine d'années à partir des études sur la famille esclave. Stuart Schwartz, dans son livre sur la région sucrière de Bahia, consacre un chapitre aux questions démographiques où il présente la classique question de l'absence d'accroissement naturel de la population esclave,

20 - Sur la notion de châtiment et de souveraineté domestique dans la société esclavagiste, voir S. Hunold Lara, Campos da violência..., op. cit., ainsi que Rafael de Bivar Marquese, Feitores do corpo, missionários da mente. Senhores, letrados e o controle dos escravos nas Américas, 1660-1860, São Paulo, Companhia das Letras, 2004.

21 - Gilberto Freyre, Casa-Grande \& Senzala, éd. par G. Giucci et al., Madrid, ALlCA XX, [1933] 2002. Dans cette édition, on trouve un commentaire très intéressant de Stuart B. SCHWARTZ, « Gilberto Freyre e a historia colonial: uma visão otimista do Brasil », p. $908-921$. 
et un autre sur «la famille esclave et les limitations de l'esclavage » qui est initiateur de nouvelles approches ${ }^{22}$. Depuis, les études sur la vie familiale des esclaves se sont multipliées sur les différentes régions du Brésil, montrant de forts contrastes ${ }^{23}$.

Il apparaît désormais clairement que, tout au long de la période de l'esclavage, les esclaves ont pu et su reconstruire des liens familiaux forts, et que les maîtres n'ont pas eu toujours intérêt à priver leurs esclaves de vie familiale. Dans ce nouveau tableau, se pose la question du mariage légitime. Le mariage devant l'Église n'était en effet qu'une forme de vie familiale parmi d'autres et, dans la société brésilienne dans son ensemble, les formes d'unions consensuelles sans intervention de l'Église étaient très répandues.

Il est difficile de se faire une idée de la proportion de mariages légitimes au sein de la population servile au début du XVIII ${ }^{\mathrm{e}}$ siècle à Salvador de Bahia, faute d'études précises. La mise en perspective de travaux concernant d'autres régions du Brésil et d'autres époques permet de se faire une idée de la complexité de la question du mariage des esclaves. Les différents critères qui peuvent expliquer les variations du taux de mariages légitimes dans la population servile sont le nombre d'esclaves appartenant au même propriétaire, leur type d'activités économiques, la proximité des ports de traite, le maillage ecclésiastique. S. Schwartz donne l'exemple, pour le XVII ${ }^{\mathrm{e}}$ siècle, des grandes propriétés bénédictines du recôncavo bahianais où toute la population servile était mariée du fait d'une politique volontariste des religieux qui achetaient des esclaves femmes pour former des couples et justifiaient cette politique matrimoniale pour des raisons, certes religieuses, mais aussi économiques et politiques (les esclaves ayant des enfants étaient plus soumis et ne fuyaient pas). Selon l'historien américain, les jésuites n'appliquaient pas cette politique sur leurs propriétés de la région de Bahia ${ }^{24}$. Dans la région rurale de la capitainerie de Rio de Janeiro au XVII ${ }^{\mathrm{e}}$ siècle, où prédominait une activité d'élevage et d'extraction du bois, Sheila de Castro Faria a montré que les maîtres préféraient la stabilité des couples mariés pour faire garder le bétail dans des endroits éloignés et isolés où la fuite aurait pu être une option. Au sein de ces propriétés, qui comptaient jusqu'à mille esclaves, les couples pouvaient se choisir librement: quand ils étaient en âge de se marier, les jeunes esclaves, filles et garçons, quittaient le lopin familial isolé et venaient résider dans les quartiers d'esclaves (senzala) pendant quelques années pour apprendre leur métier et choisir un conjoint qu'ils épousaient en légitime mariage ${ }^{25}$. En milieu urbain, où les propriétés comptaient un moins grand nombre d'esclaves, les mariages légitimes

22 - Stuart B. Schwartz, Segredos internos. Engenhos e escravos na sociedade colonial, 1550-1835, São Paulo, Companhia das Letras, 1995, chap. 13 et 14.

23 - Pour une synthèse et un bilan historiographique sur la famille esclave, voir Maria Beatriz Nizza da Silva, Historia da família no Brasil colonial, Rio de Janeiro, Nova Fronteira, 1998, chap. 4, et Robert W. SLENES, Na senzala, uma flor. Esperanças e recordações na formação da família escrava: Brasil sudeste, século XIX, Rio de Janeiro, Nova Fronteira, 1999, chap. 1.

24 - S. B. SchwarTZ, Segredos internos..., op. cit., p. 293. 
semblent avoir été plus rares. Mariza de Carvalho Soares a étudié la population africaine esclave de Rio de Janeiro au XVIII ${ }^{\mathrm{e}}$ siècle à partir des registres paroissiaux des paroisses urbaines; sur un groupe de 6609 enfants esclaves baptisés, 253 sont de mères légitimement mariées. Un couple marié ayant en général plusieurs enfants, cela fait un faible taux de mariage (le chiffre avancé est moins de $10 \%$ ) $^{26}$. Dans la région des Minas Gerais, il y a très peu de mariages : le taux d'illégitimité de la population servile atteint $98 \%$ en 1804 pour Vila Rica. Dans cette société socialement plus ouverte et mobile, le mariage ne représentait pas une option intéressante, ni pour les maîtres ni pour les esclaves. Le concubinage ou le célibat y sont plus attractifs ${ }^{27}$. Katia Mattoso, qui a analysé la population de la ville de Bahia du XIX ${ }^{\mathrm{e}}$ siècle, n'a pas trouvé une seule trace de mariage légitime d'esclaves dans toute la documentation qu'elle a consultée; selon elle, il s'agit d'une anomalie, qui reste néanmoins significative d'un très faible nombre de mariage ${ }^{28}$. Les études de Robert Slenes sur la population du Sud-Est du pays dans la première moitié du XIX ${ }^{\mathrm{e}}$ siècle montrent au contraire des taux de nuptialité relativement élevés, notamment dans la population féminine: autour de $30 \%$ dans les propriétés de moins de dix esclaves et de $65 \%$ dans les propriétés plus grandes ${ }^{29}$. En 1872 , le premier recensement officiel de la population brésilienne donne un taux de $10 \%$ de femmes esclaves mariées ou veuves. De ce kaléidoscope d'exemples, on retiendra l'idée que durant les quatre siècles de l'esclavage, il a existé des mariages légitimes d'esclaves mais que le mariage n'a été qu'une option parmi d'autres possibilités de vie familiale. Tout dépendait de l'intérêt que les maîtres, mais aussi les esclaves, trouvaient dans l'option du mariage légitime. La volonté des maîtres était cependant dominante : ceux-ci ne s'opposaient généralement pas aux unions à l'intérieur de leur propriété, en revanche ils refusaient que leurs esclaves épousent des esclaves d'autres propriétaires, sauf si ce mariage hors de leur «cheptel » leur fournissait un autre dépendant. Le critère du nombre d'esclaves par maître est alors essentiel pour comprendre le nombre de mariages légitimes. Dans le cas de petits «cheptels », notamment en ville, le mariage était donc plus rare. La volonté des esclaves comptait également dans le choix du mariage légitime. Ils pouvaient intervenir dans le choix du mariage ou du concubinage, dans le choix des conjoints avec la pratique plus ou moins forte de l'endogamie ethnique. Outre l'épineuse question du consentement du maître, les esclaves qui souhaitaient se marier étaient confrontés aux exigences de l'Église qui leur demandait, pour proclamer les bans, de fournir une série de documents (certificat de baptême, certificat de non-empêchement

26 - Mariza de Carvalho SoARes, Devotos da cor. Identidade étnica, religiosidade e escravidão no Rio de Janeiro, século XVII, Rio de Janeiro, Éd. Civilização Brasileira, 2000, chap. 3. 27 - Donald Ramos, "City and country: The family in Minas Gerais, 1804-1838 », Journal of Family History, 3-4, 1978, p. 337-360 ; Eduardo França PAIVA, Escravo e libertos nas Minas Gerais do século XVIII : estratégias de resistência através dos testamentos, São Paulo, Annablume, 2009.

28 - Katia M. de Queirós MatToso, Bahia, século XIX: uma província no Império, Rio de Janeiro, Nova Fronteira, 1992, p. 166.

29 - R. W. Slenes, Na senzala..., op. cit., p. 75. 
s'agissant des interdits d'affinité et de parenté) et de payer une somme qui était non négligeable.

C'est sur fond de ces pratiques diverses et complexes que l'Église coloniale produisit au tournant $\mathrm{du}$ XVIII ${ }^{\mathrm{e}}$ siècle une série de discours en faveur du mariage légitime des esclaves.

\section{L'Église du Brésil et le combat pour le mariage des esclaves}

On trouve une célèbre description de la vie familiale des esclaves dans les plantations de sucre de la région du recôncavo bahianais dans le traité d'économie domestique et de présentation des richesses du Brésil, écrit vers 1700 par le jésuite Andreoni sous le pseudonyme d'Antonil, et immédiatement détruit par la couronne portugaise, effrayée de voir les richesses du Brésil exposées à la convoitise des autres nations. Dans le chapitre intitulé «Comment le maître de l'habitation doit se comporter envers ses esclaves », Antonil évoque le mariage des esclaves.

Certains maîtres s'opposent au mariage de leurs esclaves, hommes et femmes, et non seulement ils n'attachent pas d'importance à leurs concubinages, mais encore c'est presque ouvertement qu'ils y consentent et y donnent naissance en disant: toi, un tel, le moment venu, tu épouseras une telle; et dès ce moment il les laisse se fréquenter comme s'ils étaient recus pour mari et femme ${ }^{30}$.

Dans ce passage, Antonil décrit très précisément un simulacre de mariage. En rapportant au style direct la formule des maîtres "Tu épouseras », il souligne combien cette pratique est éloignée des exigences du mariage chrétien selon lesquelles les époux eux-mêmes échangent leur consentement en présence du curé de la paroisse (in facie Ecclesiae) avec la formule «Je te reçois pour époux». Dans les unions décrites par Antonil, seule compte la volonté du maître, ni le consentement des conjoints ni le rite prévu par l'Église n'interviennent.

\section{Le concubinage des esclaves selon Antonil: un simulacre de mariage}

Sous la plume de ce jésuite, juriste confirmé, chargé par l'archevêque de relire les prescriptions synodales de 1707 , cette description du rite et des pratiques seigneuriales entourant les unions d'esclaves vaut condamnation malgré son apparente neutralité. La justification des maîtres à ne pas marier les esclaves est rapportée par Antonil :

Ils prétendent qu'ils ne les marient pas de crainte que, lassés du mariage, ils ne se tuent bientôt, soit en absorbant du poison, soit en recourant à des sortilèges, car il ne manque pas parmi eux des maîtres insignes dans cet art ${ }^{31}$.

30 - J. A. Andreoni, Cultura e opulência ..., op. cit., liv. I, chap. IX, "Comment le maître 
À en croire les maîtres, ce sont les esclaves eux-mêmes qui ne supporteraient pas l'état marital chrétien, monogame et indissoluble. Le renversement de point de vue est intéressant. Dans ce débat sur le mariage, maîtres d'esclaves et ecclésiastiques argumentent chacun au nom de la volonté des esclaves eux-mêmes. L'argument des maîtres est, selon Antonil, de mauvaise foi, mais il n'est pas dénué de fondement. Le mariage chrétien était considéré par les néophytes en terrain de mission comme contraignant, et les esclaves ne revendiquaient probablement pas tous de pouvoir se marier chrétiennement.

Antonil dénonce aussi le fait que les maîtres séparent les conjoints mariés, rendant de fait impossible l'union de vie que le mariage chrétien implique :

D'autres maîtres, après que leurs esclaves se sont mariés, les séparent pendant des années de telle sorte qu'ils sont comme célibataires - chose que, en conscience ils n'ont pas le droit de faire ${ }^{32}$.

Le maître revendique le droit de vendre, louer, déplacer ces esclaves au gré de ses besoins et considère le mariage comme une limitation de ce droit. La question du déplacement des esclaves prend une acuité particulière dans la société bahianaise du début du XVIII ${ }^{\mathrm{e}}$ siècle. En effet, la découverte de l'or dans les régions intérieures provoque une hausse des prix des esclaves sans précédent et, pour beaucoup de maîtres, il devient plus intéressant d'envoyer leurs esclaves dans les régions minières que de les garder dans les propriétés rurales du recôncavo bahianais. De façon générale, les fortunes étaient, dans la colonie, très fluctuantes et les esclaves étaient les biens dont on se défaisait le plus rapidement; la mobilité des esclaves était une réalité. Antonil évoque à propos de cette séparation des couples une interdiction morale.

Enfin, il conclut ce passage sur le mariage par la dénonciation de l'absence totale de préoccupation des maîtres pour le salut de leurs esclaves:

D'autres encore sont si peu soucieux de ce qui appartient au salut de leurs esclaves qu'ils les gardent très longtemps dans les champs de canne ou au moulin sans les faire baptiser ${ }^{33}$.

Dénonçant l'incurie des maîtres face à leur devoir religieux, le jésuite souligne ici le lien entre les sacrements du baptême et du mariage. Pour se marier, les esclaves devaient présenter un certificat de baptême. Or l'absence de baptême due à la négligence des maîtres était fréquente, même si elle était en principe punie par la loi tant civile qu'ecclésiastique ${ }^{34}$. De cette absence de baptême découlait,

\section{2 - Ibid.}

33 - Ibid.

34 - Selon la loi civile (Ordenações Filipinas, 1604, § 99), les maîtres étaient obligés de faire baptiser leurs esclaves dans un délai de six mois. Le baptême était obligatoire pour les esclaves âgés de moins de dix ans. Pour les esclaves âgés de plus de dix ans, la loi prévoyait qu'ils donnent leur assentiment. Au cas où les esclaves le refusaient, le maître devait en référer aux autorités ecclésiastiques et, seulement ainsi, sa responsabilité était dégagée. Les Constitutions ecclésiastiques avaient les mêmes exigences, mais 
par conséquence logique, l'absence de mariage. Inversement, le baptême des adultes était difficile si la question du mariage n'avait pas été réglée, car c'était mettre le nouveau chrétien d'emblée en situation de péché.

Pour les hommes d'Église comme Andreoni, il allait de soi que tant les maîtres qui s'opposaient au mariage des esclaves que les esclaves qui préféraient les unions «libres» étaient dans l'erreur. Ils pouvaient leur opposer la doctrine de l'Église universelle qui affirmait que le mariage chrétien et l'état de servitude étaient compatibles et que le mariage était une obligation pour tous ceux qui vivaient dans le péché. Cette vérité selon l'Église est réaffirmée avec force au Brésil en ce début du XVIII ${ }^{\mathrm{e}}$ siècle, à l'occasion de la rédaction des premières Constitutions de l'archevêché de Bahia qui sont proclamées lors du synode de 1707.

\section{Les Constitutions de l'archevêché de Bahia et le mariage des esclaves}

Les premières Constitutions ecclésiastiques de l'Amérique portugaise contiennent trois dispositions sur le mariage et le concubinage des esclaves. Dans le livre $\mathrm{I}^{\mathrm{er}}$, qui traite des sept sacrements de l'Église, le canon 303 stipule que le mariage des esclaves est un droit humain et divin et une obligation religieuse, tant pour les maîtres que pour les esclaves. Il déclare en état de péché mortel les maîtres qui empêchent les esclaves de se marier au moyen de la violence physique et des menaces et rappelle que le mariage ne libère pas de la servitude. Le canon 304 offre aux esclaves un recours pour contourner l'opposition des maîtres: si les conditions requises pour célébrer le mariage - connaissance par les esclaves de la doctrine religieuse et des obligations du mariage chrétien - se trouvent remplies, l'archevêque donnera son autorisation pour le célébrer, nonobstant l'opposition du maître. Enfin, le canon sur le concubinage des esclaves, qui se trouve dans le livre consacré aux délits et châtiments (livre $\mathrm{V}, \S 989$ ), complète les dispositions sur le mariage : il souligne la responsabilité des esclaves dans le crime de concubinage et prévoit des sanctions, comme la prison et l'exil, entraînant la séparation des couples pour les esclaves concubinaires qui refuseraient de se marier. La responsabilité des maîtres est aussi évoquée, mais elle est moins sanctionnée.

En dotant l'archevêché de Bahia de Constitutions qui lui soient propres, l'archevêque Sebastião Monteiro da Vide vise à rehausser son prestige et à réaffirmer l'importance du droit pour corriger des pratiques locales parfois déviantes. Jusqu'à cette date, ce sont les Constitutions de l'archevêché de Lisbonne qui s'appliquaient en Amérique portugaise. L'objectif est de promouvoir au Brésil la législation canonique universelle de l'Église, basée sur l'Écriture, les Pères de l'Église, les conciles et les recueils de droit canonique. L'archevêque ne cherche ni à innover ni à souligner les spécificités de son nouvel archevêché, il vise au contraire à marquer l'intégration de ce dernier dans le giron de l'Église universelle. Monteiro da Vide est un juriste formé à l'université de Coimbra, il est un spécialiste du droit du mariage puisqu'il a été juge des mariages de l'archevêché de Lisbonne 
de 1682 à 1690. L'archevêque de Bahia connaît parfaitement les Constitutions de Lisbonne et, sur le sujet du mariage des esclaves, il les recopie quasi intégralement dans les Constitutions de l'archevêché de Bahia ${ }^{35}$ - le décret des Constitutions de Lisbonne de 1646 reprenant lui-même un premier décret de l'archevêque de Lisbonne sur le mariage des esclaves datant du 30 mai $1568^{36}$. La seule différence notable entre le texte de Bahia et celui de Lisbonne sur la question du mariage des esclaves est l'allusion à une bulle de Grégoire XIII sur le mariage chrétien des esclaves nouvellement convertis de 1585.

La question du mariage des esclaves n'est donc pas traitée dans les Constitutions comme une question en suspens, spécifique à la société brésilienne, que l'archevêque chercherait à résoudre directement, mais comme un débat théorique sur lequel l'Église a déjà statué ${ }^{37}$. Cela est parfaitement visible si l'on examine les références contenues dans les très nombreuses notes de bas de page. La première note du paragraphe 303 peut ainsi servir d'exemple afin de montrer comment l'Église coloniale du début du XVIII ${ }^{\mathrm{e}}$ siècle sollicite un corpus d'autorités juridiques et théologiques pour répondre à des questions d'actualité ${ }^{38}$. La note renvoie d'abord au Décret de Gratien (1140) ${ }^{39}$ et aux Décrétales de Grégoire IX (1234) ${ }^{40}$, qui sont les deux plus anciennes collections de décrets

35 - Le paragraphe sur le mariage dans les Constitutions synodales de l'archevêché de Lisbonne de 1646 se trouve au liv. I, titulo XIII, decreto VIII «Dos casamentos dos escravos » : Rodrigo DA CunHA, Constituições synodaes do arcebispado de Lisboa..., Lisboa Oriental, Na Officina de Filippe de Sousa Villela, [1646] 1737.

36 - Constituições extrauagantes do arcebispado de Lisboa, tit. V, const. I, fol. 99v. Cette référence se trouve dans Didier LAHON, «Esclavage et confréries noires au Portugal durant l'Ancien Régime (1441-1830)", thèse, EHESS, Paris, 2001, p. 144.

37 - Dans l'historiographie, les Constitutions ont habituellement été lues comme des réponses directes et spécifiques aux difficultés de la société coloniale, sans étudier le détour canonique par lequel passent les autorités pour répondre à ces difficultés. S. B. SchwarTz, Segredos internos..., op. cit., p. 315 ; Luiz Felipe DE Alencastro, O trato dos viventes. Formaşão do Brasil no Atlântico Sul, séculos XVI e XVII, São Paulo, Companhia das Letras, 2000, p. 160-162.

38 - Voici la note: «Cap. 1. cap. 2. cap. Si quis ingennuus 4. cap. Si foemina 5. 29. q. 2. c. 1. de Conjug. servor. D. Thom. in 4. dist. 36. q. unic. art. 2. in corpore. Sanch. de Matrim. lib. 7. d. 21. à n. 3.".

39 - La première référence de la note "Cap. 1. cap. 2. cap. Si quis ingennuus 4. cap. $\mathrm{Si}$ foemina 5. 29. q. 2. » renvoie au Décret de Gratien (1140), deuxième partie, cause 29, question II ; chap. 1, «Licet seruis matrimonia contrahere» (Il est permis aux esclaves de contracter mariage); chap. 2, "Ancillam in matrimonio susceptam uiro dimittere non licet» (Il n'est pas permis à un homme de renvoyer une esclave après le mariage); chap. 4 , «De eo, qui ancillam ducit in uxorem, quam putat liberam esse » (À propos de celui qui a épousé une esclave croyant qu'elle était libre); chap. 5, «Non licet mulieri dimittere quem sciens seruum accepit in uirum » (il n'est permis à la femme de renvoyer celui qu'elle a épousé sachant qu'il était esclave).

40 - La deuxième référence, «c. 1. de Conjug. Servor », renvoie à la décrétale De conjugio servorum (Du mariage des esclaves), tit. IX du liv. IV. Voici le début de cette décrétale: «Servus, contradicente domino, matrimonium contrahere potest; sed propter hoc non liberatur a servitiis domino debitis » (Un esclave malgré l'opposition de son maître peut contracter mariage; mais du fait de son mariage, il n'est pas libéré des services dus à son maître). 
canoniques constituées à partir des décisions des papes et des conciles; elles sont à la base du Corpus Iuris Canonici, recueil de droit officiel de l'Église, confirmé en 1580 par le pape Grégoire XIII, et qui continue donc d'être pour l'époque moderne la base de l'enseignement et de la pratique judiciaire de l'Église. La doctrine classique du mariage telle qu'elle s'est fixée aux XII ${ }^{\mathrm{e}}$ et XIII ${ }^{\mathrm{e}}$ siècles est représentée dans la note par la référence aux Sentences de Pierre Lombard et à son commentaire par Thomas d'Aquin ${ }^{41}$ un siècle plus tard, forme d'apogée de la doctrine théologique. Thomas Sánchez représente l'apport de la théologie du XVI ${ }^{\mathrm{e}}$ siècle sur le mariage ${ }^{42}$, son ouvrage étant une synthèse de la pensée sur le mariage de la seconde scolastique produite par les théologiens ibériques. La note de bas de page contient enfin l'apport des conciles : celui de Florence de 1434, où le mariage a pris définitivement place dans la liste des sept sacrements, et bien sûr le concile de Trente, qui a promulgué des décisions importantes concernant le mariage lors de la session de 1563, notamment le décret Tametsi qui précise le rite à observer pour la célébration des mariages afin d'éviter les mariages clandestins ${ }^{43}$. Cet infratexte, qui renvoie au droit canonique, à la théologie médiévale et aux apports du XVI ${ }^{\mathrm{e}}$ siècle, est aisément accessible à quiconque dispose d'une bibliothèque bien fournie, sans doute rare dans la Bahia du début du XVIII ${ }^{\mathrm{e}}$ siècle, à l'exception de la bibliothèque du collège des jésuites. L'objectif de l'archevêque n'est sans doute pas d'inviter le lecteur des Constitutions à aller lire l'ensemble des textes sollicités, mais de signaler le statut d'autorité du texte. Les canons sur le mariage ne contiennent que des références à des autorités reconnues. Il est significatif qu'en soit absente l'œuvre du jésuite italien moraliste Benci, qui apparaît à d'autres reprises dans les Constitutions notamment sur l'obligation que les maîtres ont de dispenser la doctrine religieuse à leurs esclaves ${ }^{44}$. Bien que contenant de longs développements sur le mariage, l'œuvre de Benci n'est pas citée dans les canons sur le mariage car

41 - La référence dit «D. Thom. in 4. dist. 36. q. unic. art. 2. in corpore». Cela renvoie à la distinction 36, question unique des Sentences de Pierre Lombard (1158-60) qui comporte quatre points sur le mariage des esclaves. Le commentaire de Thomas d'Aquin sur la question de Pierre Lombard présente cinq articles avec à chaque fois l'exposé des difficultés et leur solution. C'est l'article 2, «Utrum servus matrimonium contrahere possit sine consensu domini » (un esclave peut-il contracter un mariage sans le consentement de son maître ?), qui est ici sollicité : S. TOMmaSo D’AQuino, Commento alle sentenze di Pietro Lombardo, Bologne, ESD, 2001, vol. 9.

42 - La dernière référence de cette première note est le livre de R. Patris Thomae SÁNCHEZ, De sancto matrimonii sacramento disputationum tomi tres, Lugduni, sumptibus Societatus typographorum, [1599] 1621, liv. 7, dist. 21, nº 3. Le livre VII de l'ouvrage de Sánchez est consacré à la discussion des empêchements de mariage. La dispute XXI porte sur le point suivant, «An servi possint invitis dominis matrim. Inire nefasque sit impedire: $\&$ an conjugi potius quam domino satisfacere teneantur» (Les esclaves peuvent-ils se marier contre l'avis de leur maître?).

43 - Le décret Tametsi est publié par Giuseppe Alberigo (dir.), Les conciles acuméniques, Paris, Éd. du Cerf, 1994, t. II-2, p. 1530.

44 - J. Benci s.j., Economia cristã..., op. cit. Sur l'influence de Benci dans les Constitutions, da Bahia de 1707 », Revista Eclesiástica Brasileira, 267, 2007, p. 609-624. 
elle n'a pas le statut de référence théologique et juridique. Le mariage des esclaves est ainsi présenté comme une question tranchée sur laquelle l'Église du XVIII ${ }^{\mathrm{e}}$ siècle ne peut innover.

\section{Liberté du mariage et esclavage selon le droit canonique et la théologie}

Le canon 303 du livre I des Constitutions contient trois propositions principales : les esclaves peuvent se marier selon le droit divin et humain, avec d'autres personnes captives ou avec des libres; les maîtres ne peuvent empêcher les esclaves ni de se marier ni de jouir du mariage; les esclaves, une fois mariés, restent esclaves. Ces propositions résument toute la doctrine de l'Église sur le mariage des esclaves qui s'est construite en opposition au droit romain ${ }^{45}$. En effet, l'Église primitive reconnaît le droit des esclaves à se marier en s'appuyant sur l'idée de l'égalité chrétienne des enfants de Dieu, formulée par saint Paul dans l'Épître aux Galates (Gal. 3, 28). Cependant, après la christianisation de l'empire, l'Église ne modifie pas le droit séculier romain sur ce point. Le mariage des esclaves est une exigence de la morale chrétienne, mais n'a pas d'existence juridique pendant la période antique. Au cours du haut Moyen Âge, l'esclavage ne disparaît pas et coexiste avec d'autres formes de domination, moins absolues, comme le servage. Les textes restent néanmoins ambigus, car le même mot latin servus désigne l'esclave ou le serf. Le droit coutumier a tendance à imposer des formes d'unions inférieures pour les servi avec, notamment, la nécessité du consentement des maîtres pour le mariage. Dans la doctrine classique du mariage élaborée aux XII ${ }^{\mathrm{e}}$ et XIII ${ }^{\mathrm{e}}$ siècles par les canonistes et les théologiens, le thème du mariage des esclaves ou des serfs est toujours abordé. Thomas d'Aquin effectue une synthèse des différents auteurs et ses développements théologiques sont des explications des décrets des canonistes. Son influence est tout à fait perceptible dans le texte des Constitutions, à la fois dans le texte principal et dans les notes.

La démonstration que l'esclavage est compatible avec le mariage passe par la distinction des trois sortes de droit. Le droit divin a été voulu par Dieu, le droit naturel est lié à la nature humaine telle qu'elle a été voulue par Dieu et, enfin, le droit positif a été inventé par l'homme. Le mariage et l'esclavage ne sont pas sur les mêmes registres de droit. Le mariage est une institution de droit divin et humain qui a été voulue par Dieu pour l'homme et la femme avant la chute d'Adam et Ève pour la reproduction de leur espèce. L'esclavage, la domination de l'homme sur l'homme, est en revanche de droit positif et est une conséquence du péché des hommes. Dieu n'a pas désiré l'esclavage, qui est donc contre la nature, alors que le mariage est selon la nature. Une institution de droit positif ne peut empêcher une institution de droit naturel. L'esclavage n'est donc pas incompatible avec le mariage.

45 - Les pages qui suivent s'appuient essentiellement sur l'ouvrage de J. GAUDEMET, Le mariage en Occident..., op. cit., où la question du mariage des esclaves est traitée pour chaque période (Antiquité, haut Moyen Âge, Moyen Âge central). Pour la période classique, voir p. 215. 
La deuxième démonstration prouve que le consentement des maîtres n'est pas nécessaire au mariage des esclaves. Selon les usages de la discussion scolastique, les arguments en faveur du consentement des maîtres sont d'abord examinés. Le premier point rappelle que personne ne peut céder à une tierce personne ce qui appartient à un autre sans la permission de ce dernier. Or l'esclave appartient au maitre; il ne peut donc céder à la femme le pouvoir sur son propre corps en contractant un mariage sans l'accord de son maittre. Les différents arguments en faveur de la nécessité du consentement du maître pour le mariage des esclaves ${ }^{46}$ sont cependant balayés par la force des arguments contraires qui sont d'ordre théologique et juridique:

Mais, au contraire, on lit Gal. 3, 28: en Jésus-Christ il n'y a plus ni esclave ni homme libre, pour contracter un mariage dans la foi de Jésus-Christ, c'est la même liberté pour les libres et pour les esclaves. De plus l'esclavage est de droit positif. Le mariage en revanche est de droit naturel et divin. Le droit positif ne peut préjudicier le droit naturel ou le droit divin, il semble donc que l'esclave puisse contracter mariage sans l'accord du maître ${ }^{47}$.

Thomas développe alors les arguments en faveur de la totale liberté de l'esclave de se marier. Le sacrement de mariage doit être entièrement libre, mais cela n'implique pas une libération de l'esclavage qui est légitime selon le droit positif. L'esclave, malgré son mariage, reste esclave et totalement soumis au maître pour son service. Le droit canonique, tout en proclamant la liberté du sacrement, nie tout pouvoir libérateur du sacrement.

La présentation de ces débats permet de montrer que les arguments en faveur du nécessaire consentement des maîtres pour le mariage des esclaves sont nombreux et fondés. D'ailleurs certains canonistes ne se rangent pas totalement aux arguments de Thomas d'Aquin et continuent de défendre la nécessité du consentement du maître. Duns Scot, notamment, en accord avec la doctrine séculière, exige le consentement du maitre si le mariage risque de compromettre les profits que le maître tire de son serf. Cependant, malgré ces dissonances, c'est la thèse de la liberté du mariage des esclaves qui prévaut.

46 - Le second argument rappelle que l'esclave est tenu d'obéir à son maître; si le maître lui commande de ne pas consentir au mariage, l'esclave ne peut contracter mariage sans le consentement du patron. Le troisième argument porte sur la contradiction qui peut exister entre le devoir conjugal que l'esclave doit à son conjoint (l'acte charnel) et le service que tout maître est en droit d'exiger de son esclave. Si le maître a besoin de son esclave pendant l'acte charnel, l'esclave est empêché de lui obéir. Le maître serait alors, sans avoir fauté, privé des services de son esclave. Ce point renvoie précisément à la situation où un esclave se rend chez son conjoint la nuit et délaisse la maison de son maître. Le quatrième argument rappelle que le maître a le droit de vendre l'esclave dans une région lointaine où sa femme ne pourrait pas le suivre. Le dernier argument rappelle qu'un esclave ne peut entrer dans les ordres religieux sans le consentement de son maître. Or, le service divin étant par nature supérieur au service dû à l'époux, l'autorisation du maître devrait être nécessaire au mariage.

47 - S. Tommaso d’Aquino, Commento alle sentenze di Pietro Lombardo, op. cit., vol. 9, p. 58. 
Les Constitutions présentent ainsi la doctrine classique sur le mariage des esclaves. La dimension religieuse et sacramentelle du mariage l'emporte dans le droit canonique sur toutes les autres logiques. Le débat autour du consentement des maîtres d'esclaves peut être rapproché de celui du consentement des pères de famille. Sur ces deux points, l'Église a cherché à imposer une logique différente de celle de la société ${ }^{48}$.

La particularité du droit canonique exposé dans les Constitutions de Lisbonne ou de Bahia apparaît clairement si on les compare sur le point du mariage au Code noir rédigé pour les colonies françaises en 1685. Le Code noir, qui relève du droit civil, reconnaît le droit des esclaves à se marier, mais stipule la nécessité du consentement des maîtres.

Article 11 : Défendons très expressément aux curés de procéder aux mariages des esclaves, s'ils ne font apparoir du consentement de leurs maîtres. Défendons aussi aux maîtres d'user d'aucune contrainte sur leurs esclaves pour les marier contre leur gré.

Le droit civil interdit au curé de marier les esclaves sans le consentement des maîtres, ce que le droit canonique autorise. Cependant, le Code noir interdit également de marier les esclaves de force, leur consentement reste fondamental. Dans le cas de la société portugaise de l'époque moderne, le droit civil respecte le monopole du droit canonique sur la question des mariages et ne statue pas sur le mariage des esclaves ${ }^{49}$.

Le principe de l'égalité chrétienne de tous les enfants de Dieu, esclaves compris, ne correspond cependant pas aux pratiques de la société esclavagiste brésilienne où le mariage des esclaves est suspendu au bon vouloir du maître. L'Église coloniale du Brésil n'est pas une force d'opposition à l'esclavage: elle admet l'esclavage et ses membres possèdent des esclaves. Quel est le sens, pour une Église en phase avec la société esclavagiste, de rappeler le principe de la liberté du sacrement?

\section{Une mise en ordre de la société esclavagiste}

Le canon 304 des Constitutions fait référence à une bulle pontificale sur le mariage des esclaves, prononcée en 1585 par Grégoire XIII, précisément pour les esclaves

48 - L’Église a longtemps refusé d'accepter l'idée d'une limitation, par les familles, du libre consentement des époux malgré les pressions des élites de la société et du pouvoir politique Finalement, le concile de Trente, en exprimant sa détestation des mariages clandestins (ceux qui étaient conclus en catimini sans la présence des familles souvent non consentantes) et en imposant des règles strictes pour la célébration des mariages, a fini par reconnaître en partie le droit des familles à limiter le libre choix des époux. 49 - Il n'y a pas de mention du mariage des esclaves dans les Ordonnances manuelines ni dans les Ordonnances philippines: S. HunOLD LARA, « Legislação sobre escravos... », art. cit. 
du Brésil récemment convertis, qu'ils soient d'origine indienne ou africaine ${ }^{50}$. La papauté, à la demande des jésuites, est donc déjà intervenue en faveur du mariage des esclaves du Brésil, à un moment où elle restait silencieuse à l'égard de l'institution de l'esclavage qui se développait massivement dans les colonies ibériques. C'est la preuve que le mariage des esclaves est considéré comme une question importante qui se pose de manière ancienne au Brésil. Le parallèle entre la bulle du $\mathrm{XVI}^{\mathrm{e}}$ siècle et les Constitutions du début du XVIII ${ }^{\mathrm{e}}$ siècle permet de réfléchir aux enjeux véritables de la défense du mariage chrétien du point de vue de l'Église coloniale.

La bulle de Grégoire XIII s'inscrit dans le débat autour du mariage des néophytes qui est un enjeu important pour l'Église missionnaire ${ }^{51}$. Paul III en 1537, puis Pie V en 1571 avaient prononcé des bulles pour faciliter les mariages chrétiens des nouveaux convertis des Indes occidentales. Ces bulles autorisaient, sous certaines conditions et en vertu de la puissance pontificale, les Indiens nouvellement convertis à se remarier et à délaisser leur épouse du temps de l'infidélité. Or, depuis l'époque de saint Paul, l'Église considérait les mariages infidèles comme valides, donc indissolubles. Les bulles de Paul III, puis de Pie V étaient donc des concessions de privilèges exceptionnels et elles firent couler beaucoup d'encre parmi les théologiens. Le débat sur le remariage des infidèles convertis se poursuivit au Brésil dans les années 1570, mais cette fois la réflexion portait sur la question des infidèles esclaves. Le problème était de savoir si on autorisait les esclaves, séparés de leur conjoint infidèle du fait de l'esclavage, à se remarier une fois convertis. La question fut posée aux théologiens du Portugal et aux jésuites du Brésil et de l'Angola. Ils conclurent qu'il fallait une nouvelle déclaration pontificale et que le privilège concédé par Pie $\mathrm{V}$ n'était pas valide dans ce cas. La solution proposée fut de recourir à ce que les canonistes appellent le «privilège paulin ${ }^{52}$ ». Saint Paul, tout en ayant beaucoup insisté sur l'indissolubilité du mariage même infidèle, avait cependant ouvert une brèche dans ce principe d'indissolubilité. Le privilège paulin, formulé à partir de la Première lettre aux Corinthiens (1 Cor. 7, 16), stipulait que lorsqu'un époux infidèle se convertissait et que son conjoint infidèle refusait de se convertir et empêchait son époux de vivre «sans offenser son Créateur », le nouveau converti pouvait se considérer comme libre et se remarier cette fois-ci chrétiennement. Selon les théologiens, l'esclavage, qui entraînait à la fois la séparation définitive des époux infidèles, la conversion de celui qui était emmené comme esclave et l'absence de communication entre les anciens époux, devait être considéré comme un cas où le privilège paulin s'appliquait. Les esclaves convertis

50 - Josef Metzler (dir.), America pontificia primi saeculi evangelizationis 1493-1592. Documenta pontificia ex registris et minutis praesertim in Archivo secreto Vaticano existentibus, Cité du Vatican, Libreria ed. vaticana, 1991, vol. II, doc. 430 «Populis ac Nationibus », p. 1228-1230.

51 - Voir Charlotte DE CASTELnAU-L'EsTOILE, «Le mariage des infidèles au XVI ${ }^{\mathrm{e}}$ siècle : doutes missionnaires et autorité pontificale ", in «Administrer les sacrements en Europe et au Nouveau Monde. La Curie romaine et les dubia circa sacramenta ", $\mathrm{n}^{\circ}$ spécial, Mélanges de l'École française de Rome Italie-Méditerranée, 121-1, 2009, p. 95-121. p. 230-280. 
pouvaient donc se remarier dans la nouvelle société où ils vivaient, sans se soucier de leur conjoint du temps de l'infidélité car, vraisemblablement, ils ne se rejoindraient jamais plus.

Si le privilège paulin avait été discuté dans le cas du mariage des esclaves chez de nombreux auteurs dont Alonso de Veracruz, théologien de NouvelleEspagne, dans le Speculum Conjugorum (1556), la bulle «Populis ac Nationibus » de Grégoire XIII renvoyait directement à la population esclave du Brésil qui était composée d'Africains déportés et d'Indiens provenant de l'intérieur des terres:

Il arrive fréquemment que des infidèles des deux sexes, surtout mâles, mariés selon les rites de leurs peuples et provenant d'Angola, d'Éthiopie, du Brésil et d'autres régions des Indes où ils furent capturés par des ennemis, soient arrachés à leurs patries et à leurs conjoints pour se trouver déportés au loin. Si bien que tant les captifs que ceux qui sont restés dans leur patrie, s'ils se convertissent par la suite, ne peuvent avertir leurs conjoints infidèles si éloignés [au cas où ils voudraient cohabiter avec eux sans offense au Créateur]. Cela parce que l'accès à des provinces hostiles et barbares est interdit même à des messagers, ou parce que les captifs ignorent tout à fait dans quel pays ils ont été transportés, ou encore parce que la longueur du chemin constitue une difficulté majeure.

Le pape, «ému par le sort des esclaves », autorisait les curés et les jésuites à marier ces esclaves convertis sans tenir compte des anciens mariages contractés dans le temps de l'infidélité. Ce texte est l'une des rares bulles pontificales à destination des esclaves et mérite de ce fait une attention importante de la part des historiens ${ }^{53}$. Son intérêt du point de vue pontifical tient au fait que le privilège paulin était une solution, pour annuler les mariages infidèles, plus conforme à la tradition juridique et théologique que les solutions de Paul III et Pie V qui reposaient sur la seule autorité pontificale. C'est sans doute cet aspect-là qui convainquit Grégoire XIII, pape juriste et traditionnel, de l'opportunité de publier un tel texte élaboré par les jésuites du Brésil et du Portugal.

Replacée dans le contexte brésilien, la bulle de Grégoire XIII peut être perçue comme le fruit d'un intense travail de pression des jésuites du Brésil qui

53 - Cette bulle est restée largement méconnue par l'historiographie brésilienne, notamment parce que le grand historien de la Compagnie de Jésus au Brésil, le père Serafim Leite la cite de manière tronquée sans mentionner le fait qu'elle est prononcée pour les esclaves : Antonio Serafim LeITE, História da Companhia de Jesus no Brasil, Lisbonne, Livraria Portugalia, 1938-1950, vol. II (1938), p. 291. Du point de vue interne à l'Église, elle eut une postérité importante et s'appliqua à tous les infidèles convertis (et pas seulement les esclaves indiens et africains du Brésil). La mention des autres régions des Indes était d'ailleurs déjà dans le texte de 1585. La bulle fut utilisée tout au long de la période moderne par les missionnaires qui désiraient marier des nouveaux convertis sans se soucier des anciens mariages du temps de l'infidélité; elle fut intégrée au Code de droit canonique de 1917 où elle est citée in extenso comme seulement huit autres textes pontificaux: Codex iuris canonici P̈̈ X Pontificis Maximi iussu digestus, Benedicti Papae XV auctoritate promulgatus, praefatione... ab emo, Romae, Typis polyglottis vaticanis, 1919, doc. VIII. 
cherchaient à obtenir une bulle sur le mariage des esclaves. Dans les années 1580, la province jésuite du Brésil choisit de s'engager massivement dans la pratique esclavagiste pour pouvoir s'assurer une indépendance économique sans laquelle elle ne pouvait envisager d'accomplir sa mission de christianisation de ces nouvelles terres ${ }^{54}$. Les jésuites firent le choix d'exploiter directement les propriétés de canne à sucre grâce à leurs esclaves envoyés au Brésil par les pères d'Angola. Obtenir un texte du pape sur l'esclavage apparaissait alors comme une forme de reconnaissance, pour la province du Brésil, de son choix du pragmatisme et une manière de faire taire les critiques qui existaient en dehors mais aussi au sein de la province. En 1584, l'un des plus farouches opposants à la possession d'esclaves par les jésuites du Brésil, le père jésuite Miguel Garcia, natif de Tolède, précisait à son supérieur, le visiteur Christovão de Gouveia, que même une révélation de Dieu ou une déclaration du Saint Pontife en faveur de l'esclavage ne l'aurait pas fait changer d'avis ${ }^{55}$. La formule est intéressante et révélatrice du fait que certains jésuites, $a$ contrario de Garcia, espéraient une déclaration pontificale sur le sujet pour faire taire toute critique sur leur pratique de l'esclavage.

Le recours au pape sur le sujet du mariage des esclaves a donc permis aux jésuites du Brésil en 1585 de se sentir confortés dans leur choix de posséder, de faire travailler et de vendre des esclaves. À un moment où ce choix de l'esclavage est encore débattu au sein de la Compagnie de Jésus, la question du mariage des esclaves permet indirectement d'obtenir une reconnaissance, par la plus haute autorité de l'Église, du fait que la province brésilienne utilise de manière massive des esclaves. On comprend dès lors la messe d'action de grâce célébrée dans l'église jésuite de Salvador à l'arrivée de la bulle au Brésil.

La bulle sur les mariages des esclaves n'aborde pas la question de la légitimité de la mise en esclavage, mais le fonctionnement de la société esclavagiste et le rôle que l'Église devait y jouer. En donnant plus de facilité aux esclaves pour se remarier, la bulle signifiait que la société qui était en train de se construire au Brésil pouvait être à la fois esclavagiste et chrétienne sous les auspices du pape.

Les théologiens de Coimbra et d'Evora, comme Fernão Perez et Luis de Molina, ont directement participé à l'élaboration de la bulle de 1585. Ils pensent l'esclavage à partir d'une société esclavagiste bien réelle, celle qui existe dans l'Atlantique Sud de la fin du XVI ${ }^{\mathrm{e}}$ siècle ${ }^{56}$. Ils discutent très précisément des titres légitimes d'asservissement, mais aussi des conditions réelles de la traite entre l'Angola et le Brésil (la multiplication des guerres ethniques comme réponse aux demandes des marchands d'esclaves) et de la limitation du droit de propriété sur autrui (un maître ne peut ni tuer son esclave, ni l'empêcher de se marier). La

54 - Sur le contexte de l'esclavage et la Compagnie de Jésus au Brésil, voir Carlos Alberto de Moura Ribeiro Zeron, Ligne de foi. La Compagnie de Jésus et l'esclavage dans le processus de formation de la société coloniale en Amérique portugaise (XVI ${ }^{e}-X V I I^{e}$ siècles), Paris, Honoré Champion, 2009.

55 - Rome, Archives de la Compagnie de Jésus, Lusitania 68, 337-340v, 25 juillet 1583, de Baya, lettre de Gouveia au Général, § $4(337 \mathrm{v})$.

56 - Voir C. ZERON, Ligne de foi..., op. cit., p. 187-303. 
réponse des hommes d'Église est de proposer à ces hommes déterritorialisés que sont les esclaves d'entrer dans une société chrétienne par le baptême et le mariage.

Au début du XVIII ${ }^{\mathrm{e}}$ siècle, au moment de la proclamation des Constitutions, la bulle de Grégoire XIII, qui datait de plus de cent ans, restait d'actualité car la société bahianaise se nourrissait de la traite et de nombreux Africains, nouveaux convertis, continuaient d'arriver à Salvador de Bahia. À cette question de la conversion, s'ajoutait désormais le thème de la «confessionnalisation » des esclaves, au sens de l'acquisition d'une foi explicite. Le canon 304 prévoit que le mariage soit l'occasion de contrôler les croyances des esclaves, par la vérification de leur connaissance des principes élémentaires de la foi chrétienne (Notre Père, Ave Maria, Credo, commandements de la loi divine et de l'Église), et de s'assurer que les esclaves avaient conscience des obligations du mariage chrétien, essentiellement de son caractère indissoluble. Le canon évoque le savoir, la compréhension et l'intention des esclaves. Il s'agit bien de pénétrer les consciences et de s'assurer que les esclaves sont de vrais chrétiens au sens où l'Église l'entend dans le monde post-tridentin. Le mariage est ici envisagé par l'Église comme un instrument pour favoriser la christianisation des esclaves et la contrôler.

Ainsi, les canons sur le mariage des esclaves permettent à l'Église d'énoncer un ordre chrétien dans cette société esclavagiste. Leur fonction n'est pas d'entrer en conflit ouvert avec les maîtres d'esclaves, ni d'accéder aux demandes des esclaves par humanité ou charité, mais de déclarer solennellement que les esclaves peuvent être baptisés, instruits dans la foi et se marier. Le mariage est essentiel dans cet ordre chrétien, sans lui, les esclaves baptisés vivent dans le péché et risquent la damnation. Fruit d'un consentement volontaire, le mariage est le signe de la conversion et de la christianisation des esclaves. Il est en quelque sorte la preuve qu'esclavage et vie chrétienne sont compatibles. En énonçant cette possible mise en ordre de la société esclavagiste, les textes canoniques de 1585 et de 1707 sur le mariage des esclaves sont aussi une manière indirecte de justifier la présence au Brésil des Noirs d'Afrique, arrachés, grâce à la traite, au paganisme et convertis au christianisme ${ }^{57}$. L'Église coloniale est donc parfaitement adaptée à la société esclavagiste : en tentant de la christianiser, elle participe de sa légitimation.

\section{Jorge Benci et l'idéal de la société esclavagiste chrétienne}

Énoncer une possible mise en ordre de la société esclavagiste va de pair avec une violente dénonciation des désordres de la société existante comme dans les discours moraux adressés aux maîtres d'esclaves par le jésuite Benci, acteur important de la scène bahianaise du début du XVIII ${ }^{\mathrm{e}}$ siècle ${ }^{58}$. Ses sermons aux maîtres d'esclaves

57 - On peut rapprocher cette démarche des théories du père Antonio Vieira qui, dans le Sermão XIV do Rosário de 1633, justifie la migration des Africains vers l'Amérique comme préfiguration de leur autre migration, après leur mort, vers le paradis: Ronaldo VAINFAS, Ideologia e escravidão. Os letrados e a sociedade escravista no Brasil colonial, Petrópolis, Vozes, 1986, p. 96-98.

58 - J. BENCI s.j., Economia cristã..., op. cit. 
sont écrits à Bahia vers 1700, et publiés à Rome en 1705 par l'intermédiaire du père Bonucci, autre jésuite italien du Brésil. En 1703, Benci est rentré à Lisbonne, mais son influence se fait toujours sentir sur l'archevêque Monteiro da Vide, puisque son œuvre est abondamment citée dans les canons sur la catéchèse. Pour le jésuite italien, la société esclavagiste est une société d'obligations réciproques. Les maîtres ont des obligations envers leurs esclaves : ils leur doivent une assistance matérielle (la nourriture, le vêtement et les soins en cas de maladie), l'instruction religieuse et les sacrements, des châtiments mesurés et proportionnels aux délits commis et, enfin, un travail à accomplir (afin d'éviter l'oisiveté et l'insolence). La doctrine chrétienne, le viatique et le mariage sont explicitement présentés comme les nourritures spirituelles les plus importantes que le maître doit à son esclave. Les paragraphes 89 à 94 sont consacrés à la nécessité du mariage des esclaves et sont un exposé de la doctrine de l'Église dans le style rhétorique d'une prédication populaire. Benci y répond à l'argument des maîtres selon lequel le mariage n'est pas fait pour les esclaves, argument qu'Andreoni avait lui-même évoqué. Dans son sermon au style direct, le père Benci retourne la situation en dénonçant les maîtres indignes de l'institution du mariage:

Vous allew me dire que les mariages ne sont pas faits pour ces gens rustres; parce que même s'ils se marient, ils cessent, tant les maris que les femmes, de mener une vie commune et qu'après le mariage ils se livrent à d'encore plus grands péchés. Mais si cette raison vous paraît suffisante, que me répondrez-vous quand je vous interrogerai: combien de maîtres qui ont épousé des femmes honorables et belles, les délaissent peut-être pour une esclave, énorme, monstrueuse et vile? Après me direz-vous qu'il ne convient pas non plus que les Blancs et les maîtres se marient ${ }^{59}$ ?

Pour Benci, il y a un parallèle possible entre le comportement sexuel des esclaves et celui des maîtres blancs qui, eux, ont droit au mariage. Les esclaves ont donc droit tout autant au mariage. On peut penser aussi que le jésuite voit dans ce mariage des esclaves entre eux une solution pour éviter les unions sexuelles entre les maîtres et leurs esclaves, unions qu'il dépeint avec un grand dégoût et qui étaient très courantes dans la Bahia du XVIII ${ }^{\mathrm{e}}$ siècle. Dans le sermon de Benci, la défense du mariage des esclaves n’empêche pas une vision négative des esclaves et une forme de racialisation qui n'apparaissait pas dans les textes juridiques.

Si la fonction de ces débats ecclésiastiques autour du mariage des esclaves est d'affirmer la possibilité d'un ordre chrétien esclavagiste, on peut se demander quel est leur impact sur l'ensemble de la société. La pétition des esclaves de Bahia, envoyée au pape en 1708, est une invitation à repenser la question de la liberté du sacrement, à partir du point de vue des esclaves. 


\section{Les esclaves de Bahia et la défense du mariage}

La pétition des esclaves évoquée au début de cet article semble indiquer qu'une partie des esclaves de Bahia du début du XVIII ${ }^{\mathrm{e}}$ siècle a fait de l'accès au mariage consacré par l'Église une revendication propre, et que les esclaves ont eu eux aussi recours au droit canonique pour revendiquer le droit de se marier librement. Ce document, présenté dans la lettre du jésuite Brandolini comme émanant des esclaves eux-mêmes, est exceptionnel tant les documents provenant directement des esclaves sont rares au Brésil.

La lettre en italien du père Brandolini permet d'en savoir plus sur la pétition des esclaves. Le jésuite explique qu'au cours d'une mission publique avec d'autres pères italiens, il a pu constater la situation déplorable des esclaves bahianais qui n'osent pas demander le mariage, car leurs maîtres les maltraitent très durement s'ils en font la demande. Il annonce qu'il envoie annexé à sa propre lettre un Mémorial écrit en latin par une confrérie des Noirs dont il ne donne pas le nom. Ainsi le Mémorial des esclaves a été envoyé à Rome l'année qui suit la tenue du synode diocésain de Bahia et l'adoption des Constitutions ${ }^{60}$. Comment interpréter le recours à Rome d'une confrérie de Noirs ? Quel éclairage la pétition des esclaves apporte-t-elle sur les Constitutions de Bahia? Comment comprendre la mise en scène de la parole esclave par un jésuite italien? Les esclaves de Bahia du début $\mathrm{du} \mathrm{XVIII}^{\mathrm{e}}$ siècle ont-ils fait du mariage religieux une vraie aspiration? Telles sont quelques-unes des interrogations que peut susciter un tel document.

L'auteur du Mémorial est donc, selon Brandolini qui se présente comme un simple intermédiaire, une confrérie de Noirs. Depuis le $\mathrm{XVI}^{\mathrm{e}}$ siècle, il existe des confréries à destination des Noirs et des mulâtres au Brésil, mais ce n'est que vers la fin du XVII siècle qu'elles commencent à s'organiser, à revendiquer des statuts propres et à adresser des pétitions à la couronne et à la papauté ${ }^{61}$. La confrérie du Rosaire des Noirs de Salvador, dont les statuts ont été reconnus officiellement par la couronne portugaise en 1686, est ainsi présente au début du XVIII ${ }^{\mathrm{e}}$ siècle dans six églises de la ville de Salvador au sein desquelles elle possède des autels. C'est une confrérie «libérale» ouverte aux hommes et aux femmes, aux Noirs et aux mulâtres, aux esclaves et aux hommes libres, aux Africains et aux Créoles. Les membres de la confrérie paient un droit d'entrée et une cotisation annuelle; en

60 - Ce document apparaît dans un catalogue des archives de la Propaganda Fide comme datant de 1686 et du pontificat d'Innocent X: Giampiero SpINELLI, Regesto del volume 1 (1649-1713) della serie Congressi, America Meridionale, dell'Archivio Storico della Sacra Congregazione "de Propaganda Fide», Rome, Tesi di laurea, 1986-1987. Outre le fait que rien dans le document ne renvoie à cette datation, la lettre de Brandolini indique clairement qu'il date de 1708 .

61 - Parmi de multiples travaux sur les confréries noires au Brésil, on peut citer Antony J. R. RusselL-WooD, "Black and mulatto brotherhoods in colonial Brazil: A study in collective behavior", The Hispanic American Historical Review, 54-4, 1974, p. 567-602, et João ReIS, "Identidade e diversidade étnica nas irmandades negras no tempo da escravidão », Tempo, 2-3, 1996, p. 7-33. 
échange, ils reçoivent le droit à des funérailles chrétiennes, à certaines aides et participent à une vie religieuse commune (communion et confession une fois par mois, célébration de prières le samedi et le dimanche et grande fête annuelle au mois d'octobre). La direction de la confrérie est assurée par une Mesa, composée d'un président, d'un notaire et d'un trésorier. Il semble que souvent la charge de notaire et de trésorier soit assurée par des Blancs, ce qui est progressivement de plus en plus mal perçu par les confrères noirs; le chapelain, qui est de droit dans la Mesa, est aussi souvent un homme blanc. La présence de médiateurs, comme le père Brandolini qui a dû mettre en forme la demande des esclaves, n'est donc pas exceptionnelle.

Le recours à la papauté par une confrérie des Noirs de Bahia en 1708 est une démarche audacieuse mais qui a déjà eu des antécédents. En juillet 1686, l'année même de l'approbation par la couronne des statuts de la confrérie du Rosaire de São Salvador, le Noir affranchi, Paschoal Dias, reçoit l'autorisation de l'évêque franciscain de Bahia, Fr. João da Madre de Deus (1683-1686), de partir à Rome en tant que représentant de six confréries de Noirs de Salvador afin de porter une pétition sur le lamentable état dans lequel se trouvaient les esclaves noirs du Brésil ${ }^{62}$. Cette pétition n'a pas été retrouvée mais, en revanche, un document de la Propaganda Fide atteste que Dias parvint bien à Rome avec le titre de "Délégué et procureur des Noirs de la Direction (Mesa) des Noirs de Notre Dame du Rosaire de la confrérie de Notre Dame de l'Exil; de la confrérie de Notre Dame du Rosaire de l'Église de Saint Pierre des Noirs; de la confrérie Notre Dame du Rosaire de l'Église Notre Dame de la Conception; de deux confréries qui sont à Saint Benedito, de la confrérie de Notre Dame du Rosaire de la Cathédrale. » Dans ce document, qui a une valeur officielle et juridique, on saisit l'importance du nom des confréries. Le contraste est saisissant avec le Mémorial des esclaves de 1708 qui ne comporte aucun nom de confrérie.

L'ambassade de Dias en 1686 s'inscrit en fait dans un mouvement plus large de recours à la papauté et d'offensives contre les pratiques esclavagistes dans les empires ibériques, mené à partir des années 1680 à la fois par des religieux, principalement issus de l'ordre franciscain et notamment les capucins, et par des esclaves affranchis. Longtemps méconnu dans l'histoire de l'Église et de l'esclavage, cet épisode commence à être plus étudié ${ }^{63}$. En 1684, était ainsi venu à Rome un mulâtre d'origine afro-brésilienne, Lourenço da Silva de Mendoça, qui se disait de sang royal du Congo et qui avait le titre de procurateur des Mulâtres du royaume

62 - Arlindo Rubert, A Igreja no Brasil, Santa Maria, Palloti, 1988, voir la présentation vol. II, p. 307-308 et le document en annexe D, «Memorial em defesa dos Escravos do ano $1686 »$ p. $380-382$.

63 - Voir l'article précurseur de Richard GraY, «The papacy and the Atlantic slave trade: Lourenço da Silva, the Capuchins and the decisions of the Holy Office ", Past \& Present, 115, 1987, p. 52-68, ainsi que Hebe MATTOS, «A escravidão moderna nos quadros do Império português: o Antigo Regime em perspectiva atlântica ", in J. FraGoso, M. F. Bicalho et M. DE Fátima GouvêA (dir.), O antigo regime nos trópicos. A dinâmica p. 141-162. 
du Portugal, de Castille et du Brésil. Il apportait une série de documents pour se plaindre de l'esclavage perpétuel des esclaves chrétiens, des mauvais traitements infligés par les maîtres et pour demander l'excommunication apostolique pour ceux qui pratiquaient des sévices sur leurs esclaves ${ }^{64}$. L'année suivante, le 12 mars 1685, la Propaganda Fide examine un texte du procureur général des capucins dénonçant les abus fréquents de l'esclavage à partir des témoignages et des écrits du père espagnol Francisco José de Jaca et du père français Épiphane de Moirans, excommuniés à La Havane depuis 1681 et emprisonnés pour avoir condamné publiquement l'esclavage ${ }^{65}$. Les abus de l'esclavage (cas de servitudes illégitimes, non-respect des sacrements) dénoncés par les deux capucins sont résumés par onze propositions. La neuvième proposition concerne le mariage et le concubinage des esclaves :

\section{9- Les maîtres des nègres et des autres esclaves ne sont pas obligés d'empêcher qu'ils vivent en concubinage. Leurs éminences dirent qu'ils sont obligés ${ }^{66}$.}

Cette liste des onze propositions est envoyée pour être examinée par le SaintOffice, tribunal chargé de condamner les déviances théologiques. L'année suivante, le 20 mars 1686, le Saint-Office rend finalement son verdict et condamne les onze propositions décrivant les pratiques de l'esclavage. Comme le souligne Hebe Mattos, la Congrégation romaine accède aux demandes des capucins mais pas à celles de l'affranchi da Silva de Mendoça, à savoir l'excommunication des maîtres et la remise en cause de l'esclavage perpétuel des esclaves chrétiens. Le refus de considérer que la religion puisse avoir un quelconque effet émancipateur a des conséquences à long terme pour la question du maintien de l'esclavage ${ }^{67}$. La dénonciation des abus des maîtres à laquelle se cantonne le Saint-Office est envoyée aux nonces et à de nombreux évêques du monde ibérique. À la Curie cependant, dès les débuts de cette offensive contre l'esclavage, des voix se sont élevées en faveur d'un réalisme politique. Un rapport anonyme de 1682, sans doute issu de la Secrétairerie d'État, rappelle les intérêts financiers liés à l'esclavage et critique les dénonciations de la cruauté des maîtres comme étant largement exagérées.

Pour tous ceux, religieux ou anciens esclaves, qui s'adressent ainsi à Rome pour dénoncer les abus de l'esclavage, il s'agit d'utiliser la papauté comme moyen de pression pour influencer les couronnes ibériques qui règnent sans partage sur leur Église d'outre-mer, selon les principes du patronage royal établi depuis le

64 - R. GRAY, «The papacy and the Atlantic slave trade...», art. cit.

65 - On dispose aujourd'hui d'éditions critiques des œuvres des deux capucins : Francisco José DE JACA, Resolución sobre la libertad de los negros y sus originarios, en estado de paganos y después ya cristianos. La primera condena de la esclavitud en el pensamiento hispano, éd. par M. A. Pena González, Madrid, CSic, 2002; Épiphane de Moirans, Siervos libres, una propuesta antiesclavista a finales del siglo XVII, éd. par M. A. Pena González, Madrid, CSIC, 2007.

66 - Rome, Archives de la Congrégation de la Doctrine de la foi, Sant'Offizio, Decreta 1686, fol. 64rv, publié in F. J. DE JACA, Resolución sobre la libertad..., op. cit., p. 365.

67 - H. MATTOS, «A escravidão moderna...», art. cit. 
$\mathrm{XV}^{\mathrm{e}}$ siècle. Le recours au tribunal du Saint-Office est d'ailleurs stratégique, car le tribunal de l'hérésie ne se soucie pas des frontières du patronage, il a une juridiction universelle. La couronne portugaise, dont l'empire est menacé par les puissances maritimes rivales, semble avoir été attentive aux critiques émises par la papauté. C'est sans doute en partie la pression de Rome sur le roi du Portugal, par le biais du nonce à Lisbonne, qui fut ainsi à l'origine de la première législation royale de protection des esclaves. En 1688, Dom Pedro II (1683-1706) édicte plusieurs lois interdisant la pratique des châtiments abusifs et permettant aux esclaves de se tourner vers la justice royale en cas d'abus de leurs mâtres ${ }^{68}$. Les Constitutions de 1707 sont également éclairées par ce contexte de surveillance par la papauté des terres confiées au patronage. Le roi du Portugal, en envoyant au Brésil un archevêque législateur et compétent comme Monteiro da Vide pour promulguer des Constitutions, cherche sans doute aussi à montrer sa volonté de reprise en main des diocèses d'outre-mer. Dom Pedro II écrit d'ailleurs deux lettres à l'archevêque pour lui dire de veiller personnellement à la christianisation des esclaves. Cette préoccupation officielle du roi pour les esclaves est aussi une manière de donner des gages à la papauté de son intérêt pour la christianisation de ces terres lointaines ${ }^{69}$.

Le Mémorial sur le mariage, adressé par des esclaves de Bahia au pape, n'est donc pas une initiative isolée, il s'inscrit, de manière consciente ou non de la part de ces auteurs, dans un mouvement plus ample. À cause de la date et de son contenu même, on peut avancer l'hypothèse qu'il soit une réaction aux Constitutions jugées insuffisantes sur la question du mariage. Le jésuite italien précise dans sa lettre qu'il a cherché en vain à convaincre en confession des esclaves concubinaires de se marier. Il ajoute que les esclaves pourraient se marier s'ils se présentaient devant le curé, mais que la vraie difficulté est que les esclaves ne veulent pas se marier, à cause des supplices qu'ils encourent de la part de leurs maîtres ${ }^{70}$. La mention de la possibilité qu'ont les esclaves de se marier devant le curé sans le consentement de leur maître semble être une allusion aux Constitutions qui offraient cette possibilité au livre I, canon 304. Le jésuite juge cependant cette possibilité insuffisante, car elle est annihilée par la violence des mâtres. Sur ce point, les archives ecclésiastiques confirment que peu d'esclaves au Brésil

68 - Sur cette législation civile, voir S. HunOld LaRA, Campos da violência .., op. cit., p. 64; Carlos Alberto de Moura Ribeiro ZERON, «O governo dos escravos nas Constituições Primeiras do Arcebispado da Bahia e na legislação portuguesa: separação e complementaridade entre pecado e delito ", in B. Feitler et E. SAlEs Souza (dir.), A igreja no Brasil colônia. Normas e práticas no tempo do arcebispo d. Sebastião Monteiro da Vide, São Paulo, Ed. UNIFESP, 2010, sous presse.

69 - Voir Bruno Feitler et Evergton SAles Souza, «Présentation», in S. Monteiro DA VIDE, Constituições primeiras do Arcebispado da Bahia..., op. cit., p. 15.

70 - APF, vol. I (1649-1713), série Congressi, America Meridionale, doc. 163, fol. 466rv470rv: "E la ragione si è, non perché di quello [non] possano xxx di verità se si presentano o a vicarj o a curati gli xxx-sano, Ma perche nol [= non lo] vogliano à cagion [à cause de] de supplizi che incorrano coi lor Padroni. » Je remercie Giovanni Pizzorusso de son aide pour la transcription de ce texte. 
demandaient le mariage sans le consentement des maîtres. Dans les procédures de bans de mariage d'esclaves, l'autorisation des maîtres, théoriquement non nécessaire, accompagne très souvent les autres papiers exigés par l'Église ${ }^{71}$. Cela semble indiquer que dans la pratique, au Brésil, les esclaves ne pouvaient pas se marier sans le consentement de leur maître. Par contre, à Lisbonne où les Constitutions prévoyaient aussi la possibilité pour l'évêque de marier sans autorisation des maîtres, on trouve dans les archives des centaines de dossiers de mariages d'esclaves conclus sous la protection particulière de l'archevêque ${ }^{72}$. Cette différence, qui demande à être confirmée par une enquête plus systématique, signalerait que les esclaves avaient une plus grande autonomie à Lisbonne qu'au Brésil et que l'Église y était plus puissante pour imposer ses vues aux maîtres d'esclaves.

À la fin de sa lettre, Brandolini annonce qu'à cause de la «dignité de la cause », il recommande à l'attention de sa Sainteté un écrit de la confrérie dont il souhaite qu'il obtienne une réponse favorable. Quant à lui, il s'est contenté de décrire les maux, sans proposer de solution ${ }^{73}$. Il y a là une véritable mise en scène de la parole des esclaves. En effet, même si les esclaves s'expriment à la troisième personne du pluriel dans un langage très ecclésiastique, le Mémorial est présenté comme émanant des esclaves. Les esclaves « des deux sexes » adhèrent à la forme du mariage proposé par l'Église, comme remède aux péchés de la chair et comme voie vers le salut de leur âme. Ils demandent au pape des sanctions efficaces contre les maîtres afin de pouvoir effectivement se marier. L'enjeu n'est sans doute pas pour Brandolini de montrer ce que pensent les esclaves du mariage, mais la parole des esclaves a ici une valeur juridique. C'est avant tout, semble-t-il, une manière de prouver la volonté des esclaves, hommes et femmes, de se marier. Selon le droit canonique, le sacrement du mariage consiste en effet dans le consentement que les époux se donnent eux-mêmes en présence de l'Église. La mention, dans la pétition, des esclaves «des deux sexes» s'explique dans cette perspective juridique : dans le mariage, le consentement de la femme est aussi important que celui de l'homme.

Contre les mauvais traitements que les maîtres leur réservent quand ils désirent se marier, les esclaves de Bahia demandent une protection spéciale du pape: une excommunication apostolique qui est qualifiée de «seul espoir pour effrayer les maîtres », l'expression semble indiquer que les peines prévues par les Constitutions sont jugées insuffisantes. L'excommunication est une arme puissante qui va, en effet, bien au-delà des peines prévues dans les Constitutions pour les maîtres qui refusaient le mariage de leurs esclaves: ils étaient simplement déclarés en état de péché mortel (I, § 303), et leur conscience lourdement chargée

71 - M. B. Nizza da Silva, Historia da família..., op. cit., p. 191.

72 - Lisbonne, Archivo Torre do Tombo, fonds Sumarios matrimoniais. Pour l'année 1690, D. LAHON, «Esclavage... », op. cit., p. 144-150, a compté 30 dossiers de mariages d'esclaves. 73 - APF, vol. I (1649-1713), série Congressi, America Meridionale, doc. 163, fol. 466rv470rv, « La dignita della causa mi fa xxx ardire in raccomandarla alla sua saggia condotta. La confraternità sopradetta bramarebbe da $\mathrm{S}$. S. tà un benigno rescritto al memoriale qui annesso. In quanto a me bastami di aver rapresentato li mali a Va Sra. » 
( $\mathrm{V}, \S 989)$. Le péché mortel est certes une condamnation grave qui signifie la mort de l'âme, la privation de la vie surnaturelle et la destination de l'enfer en cas de mort, mais c'est une condamnation au for interne, liée au pouvoir de l'Église de juger la conscience de chaque individu et faite en privé ${ }^{74}$. Dans la société coloniale brésilienne, beaucoup de chrétiens vivaient en état de péché mortel qu'ils confessaient au moment de leur mort et expiaient par des donations. La qualification d'acte comme péché mortel n'avait pas les mêmes effets que l'excommunication qui était publique et qui impliquait de graves conséquences sociales. L'excommunication apostolique est une censure qui exclut un pécheur de la communauté des fidèles. L'excommunié est privé du droit d'assister aux offices, des sacrements et de sépulture ecclésiastique. La levée de l'excommunication apostolique doit être publique, et elle est réservée au pape ${ }^{75}$. Les esclaves demandent donc une condamnation au for externe pour les maîtres qui les empêchent, de fait, de se marier. En l'état, sans l'arme de l'excommunication apostolique, la législation canonique est jugée par Brandolini et les esclaves comme insuffisante pour lutter contre le refus des maîtres à marier leurs esclaves. Cette demande de 1708 fait du coup apparaître les Constitutions de 1707 comme inefficaces, voire laxistes, dans la lutte contre les excès de la souveraineté domestique.

Il est difficile de démêler dans le Mémorial de 1708 ce qui vient des esclaves eux-mêmes et ce qui vient du médiateur ecclésiastique. On peut néanmoins éclairer et tenter de comprendre l'engagement des différents acteurs. Dans sa lettre, Brandolini évoque son départ imminent pour l'Inde et mentionne «les missionnaires italiens» avec qui il a fait une mission publique quelques jours auparavant. Les missionnaires italiens constituent de fait un groupe particulier dans la province jésuite du Brésil ${ }^{76}$. C'est au retour du père Vieira de Rome en 1681 que les Italiens sont arrivés nombreux au Brésil, notamment le père Andreoni et le père Benci, déjà évoqués. Bien formés, ils occupent rapidement les charges supérieures de la province, suscitant la jalousie des jésuites portugais et brésiliens. Les Italiens ont une vision paroissiale de la mission auprès des Indiens et s'opposent clairement à ce que les jésuites administrent temporellement les villages des indiens (aldeamentos), qui sont une des bases de la puissance jésuite au Brésil depuis le milieu du $\mathrm{XVI}^{\mathrm{e}}$ siècle. Dans les années 1690, l'opposition dégénère en un conflit violent au sein de la province entre les partisans de l'administration temporelle des aldeias, dont le chef de file est le vieux père Vieira qui meurt en 1697, et les adeptes de l'abandon de cette forme d'administration derrière le père Andreoni. Finalement, la faction d'Andreoni l'emporte mais un décret du général de 1698, prenant acte des querelles de personnes au sein de la province et de la place prépondérante des Italiens au collège de Bahia où ils occupent quasiment toutes les charges, demande la dispersion des Italiens. Certains rentrent en Italie comme le père Bonucci; le père Benci part à Lisbonne. Andreoni, lui, reste au Brésil: il est indispensable à

74 - «Péché », in R. NAZ, Dictionnaire de droit canonique, op. cit., t. VI, p. 1284, et « For », ibid., t. V, p. 871-874.

75 - « Excommunication», ibid., t. V, p. 615-617.

76 - G. ZERON, «O governo dos escravos... », art. cit. 
la province à cause de ses talents de juriste et il occupe d'ailleurs la charge de provincial de 1706 à 1709.

On peut noter qu'à ce moment, ce sont exclusivement des jésuites italiens qui écrivent sur la question du mariage des esclaves, même si le thème avait déjà été abordé par Vieira dans ses sermons: le juriste Andreoni dans son traité d'économie domestique; le moraliste Benci dans ses sermons qui sont édités à Rome en 1705 par l'intermédiaire du père Bonucci expulsé du Brésil. Cette publication fait ainsi connaître en haut lieu les misérables pratiques des maîtres brésiliens. Enfin, c'est Brandolini, de passage au Brésil, qui suscite et transmet à Rome une demande d'esclaves en vue d'excommunier les maîtres empêchant les esclaves de se marier.

Il est intéressant de noter que chacun de ces auteurs revendique dans ses écrits son statut d'étranger. Dans la préface à ses discours, Benci se présente comme «un missionnaire étranger » et Brandolini, dans sa lettre, comme un missionnaire italien en instance de départ pour l'Asie. Quant à Andreoni, bien que très bien intégré dans la province, il signe son traité sous un pseudonyme, "le Toscan Anonyme ». Il y a là une forme de regard distant sur une société esclavagiste et coloniale qui porte à la description, voire, dans certains cas, à des dénonciations.

Il est clair également que les Italiens possèdent des réseaux à la Curie et qu'ils pensent naturellement à se tourner vers Rome. Brandolini écrit au cardinal secrétaire d'État, Fabrizio Paolucci, qu'il semble connaître personnellement. Quant à Bonucci, il arrive à faire publier à Rome le recueil de sermons de Benci en portugais sur le lointain Brésil, ce qui est le signe d'une influence certaine. Il y a, dans ces années-là, un véritable intérêt de la Curie romaine pour «l'état de la chrétienté au Brésil et au Maragnan », ainsi qu'en témoigne l'existence d'un rapport écrit par l'archevêque de Damasco, Vicenzo Petra, assesseur du Saint-Office, à l'attention de la Propaganda Fide et du pape Clément XI (1700-1721) à partir de la documentation transmise par la Propaganda Fide ${ }^{77}$. Dans son rapport sur la chrétienté du Brésil, Petra fait état de trois problèmes, le manque de sacrements, la cruauté des Européens qui empêchent le mariage des esclaves et la mise en esclavage illégitime des Indiens du Maragnan. Pour le premier point, l'information a suivi la voie officielle: une lettre du nonce du Portugal qui évoque le faible nombre de paroisses sur le territoire brésilien. Pour les deux derniers points, il s'agit de réseaux d'information, officieux, voire secrets, et ce sont des jésuites italiens qui sont à l'origine de l'information: le père Brandolini pour le mariage des esclaves et le père Bonomi pour l'esclavage illicite des Indiens du Maragnan.

Cet exemple montre que l'information parvient difficilement à Rome, mais une fois arrivée, elle est traitée par la bureaucratie romaine et circule de la congrégation de la Propaganda Fide à celle du Saint-Office, et vice versa, et est lue par des consulteurs qui la résument et proposent leur avis au pape ${ }^{78}$. Petra évoque dans

77 - APF, vol. I (1649-1713), série Congressi, America Meridionale, f. 88-93v.

78 - Sur cette circulation de l'information en provenance des terres de missions lointaines dans les bureaucraties romaines, voir «Administrer les sacrements en Europe... », op. cit., particulièrement l'article de Paolo Broggio, Charlotte DE CAstelnau-L'Estoile 
son rapport la lettre de Brandolini et le Mémorial, écrit par «les esclaves chrétiens eux-mêmes » (li stessi schiavi xpiani). Il retient de l'intervention directe des esclaves dans le Mémorial leur souci pour «leur propre salut». La voix des esclaves par le biais du Mémorial pénètre ainsi jusqu'au cœur des réseaux romains. Leurs souffrances, leur salut spirituel sont évoqués longuement par ce cardinal de la Curie.

L'engagement de Brandolini pour le mariage des esclaves est donc à replacer dans l'action plus large des jésuites italiens du Brésil en faveur d'une christianisation de la société esclavagiste. Les ouvrages de Benci et d'Andreoni s'inscrivent dans cette action de moralisation des maîtres. La démarche de Brandolini est plus audacieuse, puisqu'elle vise à obtenir une excommunication des maîtres violents et parce qu'elle met en scène les esclaves eux-mêmes, acteurs de leur propre destin. Le Mémorial n'est-il qu'un procédé rhétorique utilisé par le père Brandolini, dont on sait qu'il utilisa le même procédé au cours de sa carrière ${ }^{79}$ ? Ou bien représente-t-il aussi un réel engagement des esclaves de Bahia en faveur du mariage chrétien?

Si le style du Mémorial laisse deviner la présence d'un ecclésiastique dans la rédaction du texte, on peut penser néanmoins que les esclaves chrétiens euxmêmes ont eu un rôle d'acteurs dans cette démarche. Le Mémorial évoque, en effet, des situations conjugales concrètes: des vieux couples avec enfants qui ne peuvent accéder à la dignité du mariage, ou la séparation des couples non mariés à cause des ventes, qui était une pratique courante dans la colonie en fonction des fluctuations de la situation économique des maîtres. Enfin, le texte insiste sur un cas concret de mariage qui n'apparaissait pas dans la lettre de Brandolini: l'union entre un homme esclave et une femme libre. Or, ce mariage est le seul qui libère de l'esclavage, non pas directement les conjoints, mais leur descendance, car les enfants d'un ventre libre sont libres. Les mariages mixtes ont été étudiés pour la région de São Paulo par Eliana Goldschmidt et pour celle de de Rio de Janeiro par S. de Castro Faria selon qui, pour le XVIII ${ }^{\mathrm{e}}$ siècle, $10 \%$ des mariages des esclaves étaient mixtes ${ }^{80}$. Dans la pratique, la différence juridique entre conjoints, esclaves et affranchis ou libres, était contournée par la société coloniale par le termo de seguimento qui était un accord dans lequel la femme libre s'engageait à suivre son mari captif. De cette manière, la femme libre devenait l'égal de l'esclave, elle était agrégée à la propriété du maître de son conjoint. Dans les régions de présence

et Giovanni Pizzorusso, «Le temps des doutes: les sacrements et l'Église romaine aux dimensions du monde», p. 5-22, ainsi que celui de Giovanni Pizzorusso, «I dubbi sui sacramenti dalle missioni 'ad infideles' : percorsi nelle burocrazie di Curia », p. 39-61. 79 - On sait qu'en 1726, le père Brandolini, dans le contexte de la querelle des rites malabars, fit parvenir au pape une lettre écrite au nom des Indiens du Maduré (una sua scrittura in nome degl'Indiani del Maduré): Augustin et Aloïs DE BACKer, Bibliothèque des écrivains de la Compagnie de Jésus ou Notices..., Liège, impr. de L. Grandmont-Donders, 1861, vol. 6, p. 59.

80 - Eliana GolDSCHMIDT, «O matrimônio de mulheres forras com escravos em S. Paulo: uma estratégia de sobrevivência (1728-1822)», Anais da X Reuniao da SBPH, Curitiba, SBPH, 1991, p. 153-158; Sheila de Castro FARIA, A colônia em movimento..., op. cit., p. 316. 
indigène, cela était pour les maîtres un moyen de contourner la loi, en transformant les femmes libres (souvent indiennes) en esclaves de fait, et l'occasion de s'adjoindre une dépendante de plus. Pour les femmes libres, quelles que soient leurs origines, si elles étaient sans ressources ni métier, le mariage avec un esclave nourri ou bénéficiant d'un lopin de terre pouvait être une stratégie de survie. L'accord au bénéfice du maître n'était pas de droit, mais on comprend aisément que, sans cet accord, les maîtres s'opposaient absolument à ces mariages mixtes. Marié à une femme libre, l'esclave devenait plus autonome, notamment parce que, selon le droit canonique, les époux devaient avoir une communauté de vie.

Au début du XVIII ${ }^{\mathrm{e}}$ siècle, à Salvador de Bahia, les mariages mixtes entre esclaves et libres, notamment dans la population africaine, devaient représenter une option courante à la fois pour des raisons démographiques et pour des raisons de stratégies personnelles. Il y avait deux fois plus d'affranchissement de femmes que d'hommes, alors qu'il existait un fort déséquilibre du ratio sexuel dans la population esclave africaine, car les hommes étaient deux fois plus nombreux que les femmes dans les contingents annuels d'Africains ${ }^{81}$. Les femmes affranchies représentaient donc un vrai marché matrimonial; inversement, certaines affranchies ne pouvaient pas trouver d'autre conjoint qu'un esclave. Les raisons d'une telle «mésalliance» pouvaient être multiples et ne renvoient pas forcément à des questions de survie économique. Pour les esclaves, le mariage avec une femme libre devait représenter une étape sur le chemin de la liberté. Ce type de mariage impliquait en effet une plus grande autonomie de vie et une protection contre les ventes. Il pouvait aussi correspondre à l'espoir d'obtenir à plus ou moins long terme son propre affranchissement et à un projet de descendance libre ${ }^{82}$. Dans cette société esclavagiste du début $\mathrm{du}$ XVIII ${ }^{\mathrm{e}}$ siècle, la revendication de liberté est une revendication forte des esclaves ${ }^{83}$.

Ainsi la mention de ces mariages mixtes où toute la complexité de la société esclavagiste transparaît est bien le signe que le texte représente aussi le point de vue des esclaves et pas seulement celui d'un ecclésiastique, étranger à la société brésilienne et soucieux de faire respecter le droit canonique. D'ailleurs, si la démarche d'envoyer une pétition au pape reste exceptionnelle, l'historien Antony RussellWood a montré qu'il n'était pas rare au sein de l'empire portugais que des esclaves, des affranchis ou des Indiens s'adressent aux autorités judiciaires supérieures (le gouverneur, le roi) pour se plaindre des injustices dont ils étaient victimes. Il cite notamment les pétitions de deux femmes esclaves noires de la région de Bahia: Custodia en 1704 dans la ville de Salvador, et Maria do Pilar en 1705 dans le

81 - S. B. SCHWARTZ, «The manumission of slaves... », art. cit., p. 610.

82 - Il y a même une ambiguïté dans le droit royal castillan sur le pouvoir libérateur de ce type de mariage, dont on a vu que les jésuites du Brésil dès 1551 avaient tenté de la dissiper en rappelant qu'en aucun cas le mariage ne libérait de l'esclavage.

83 - Dans les statuts de 1686 de la confrérie du Rosaire des Noirs de Salvador, il est prévu que la confrérie puisse accorder des prêts pour aider ses membres à acheter leur liberté : A. J. R. RusSELL-WoOD, «Black and mulatto brotherhoods... », art. cit., p. 595, et J. REIS, «Identidade e diversidade... », art. cit., p. 20. 
recôncavo bahianais. Chacune d'elles écrit à la reine du Portugal pour se plaindre de son maître qui les oblige à «des relations illicites». La thématique du choix des conjoints et des abus sexuels n'est donc pas rare dans ce type de pétitions individuelles. Dans ces deux exemples, contemporains de notre document, la reine oblige les maîtres à vendre ces deux esclaves au prix fixé par le gouverneur. La logique de la société esclavagiste fait que l'on permet aux esclaves de changer de maître mais pas de se libérer. Cette possibilité d'appel direct aux autorités supérieures, sans passer par le cours habituel de la justice, trop coûteux pour les populations non européennes, était une forme visible du lien entre le souverain et ses vassaux et un instrument de pouvoir et de cohésion essentiel dans l'empire portugais ${ }^{84}$. Le fait que des esclaves aient pu décider d'écrire au pape pour se plaindre de leur situation conjugale s'inscrit dans le même type de démarche.

Pour le cardinal du Saint-Office chargé de relire le Mémorial, la démarche des esclaves africains de Bahia, qu'il désigne comme «les esclaves chrétiens", était avant tout religieuse. C'est la recherche du salut qui, selon lui, motivait les esclaves à demander le mariage chrétien. Cette lecture est possible: les esclaves de Bahia qui viennent de vivre une mission des jésuites italiens, c'est-à-dire une période de plusieurs jours d'intense vie spirituelle avec prédication, confession et communion, peuvent être mus par le désir de vivre selon la morale chrétienne. Dans la société coloniale brésilienne du XVIII ${ }^{\mathrm{e}}$ siècle, les esclaves ou affranchis sont majoritairement baptisés, certains Africains, notamment ceux qui proviennent du Congo, revendiquent leur christianisme ancien comme l'ambassadeur da Silva de Mendoça venu à Rome en 1684. Les esclaves peuvent se considérer comme de véritables «dévots de couleur » selon l'heureuse formule de M. de Carvalho Soares et mettre en avant leur incorporation au christianisme ${ }^{85}$. Dans quelle mesure le mariage avait-il un sens religieux pour les esclaves au Brésil au XVIII ${ }^{\mathrm{e}}$ siècle ? Les historiens ont analysé le mariage dans la société coloniale comme une union d'intérêts, une mise en commun de biens et de vie destinée à améliorer le sort des époux. Ils ont également cherché dans les stratégies matrimoniales la marque de la culture africaine et la volonté pour les femmes de rétablir les lignages. La dimension religieuse du mariage a été peu abordée, à la différence des funérailles. Le Mémorial de 1708 est un indice que le mariage a pu aussi avoir pour les esclaves un sens religieux et représenter l'accomplissement d'une identité de chrétien. On peut citer d'autres signes: en 1755, à São Paulo, Ana, esclave de la nation Mina (Guinée), demande à être dispensée de produire son certificat de baptême qui a eu lieu à Rio de Janeiro pour pouvoir épouser Custodio Duarte, mulâtre affranchi; son principal argument

84 - Antony J. R. RusselL-Wood, «Vassalo e soberano: apelos extrajudiciais de africanos e de indivíduos de origem africana na América portuguesa ", in M. B. Nizza da SiLva (dir.), Cultura portuguesa na Terra de Santa Cruz, Lisbonne, Estampa, 1995, p. 215-233. Pour ces exemples, voir la référence archivistique: Arquivo Público da Bahia, Ordens régias, vol. 7, doc. 288-289 et 299, p. 220-221.

85 - M. de Carvalho SoARes, Devotos da cor..., op. cit. Le livre analyse des statuts de confréries d'Africains à Rio de Janeiro dans la seconde moitié du XVIII siècle, qui posent comme objectifs explicites de leur confrérie la conversion de leur peuple et l'éradication de toute trace de paganisme. 
pour demander cette dispense est de dire qu'elle «a toujours été amie du service de Dieu ${ }^{86}$ ». Pour cette esclave, qui se présente comme une chrétienne fervente, le mariage avec un affranchi est peut-être une forme de promotion sociale, il est présenté aussi comme ayant un sens religieux. Il y a également de nombreux exemples, à partir de la seconde moitié du XVII ${ }^{\mathrm{e}}$ siècle, d'esclaves ou d'anciens esclaves qui se sont mobilisés pour faire reconnaître leur dignité de chrétien. Il est donc fort plausible que des esclaves se mobilisent en 1708 pour le mariage religieux. Cependant, le Mémorial des esclaves sur les mariages se différencie très nettement des autres textes des pétitions: il ne comporte pas de nom précis de confrérie, il ne revendique pas de privilèges pour des confrères, mais il évoque en général les «esclaves africains des deux sexes de Bahia » et "au-delà, ceux de tout le Brésil ». Le terme latin «Aethiopes » renvoie dans le vocabulaire ecclésiastique à l'Afrique noire en général. Dans la lettre en italien, Brandolini emploie le terme "neri », utilisant la couleur pour désigner les esclaves. Ainsi cette confrérie sans nom se présente-t-elle comme porte-parole de l'ensemble de la communauté esclave pour défendre la liberté du mariage ${ }^{87}$. La pétition renvoie l'image d'un monde esclave marqué à la fois par l'incorporation des valeurs chrétiennes et par la conscience qu'il a de lui-même. Le document de 1708 , dont la formulation doit beaucoup au jésuite Brandolini, ne constitue certes pas une preuve que cette conscience existe. Il n'est cependant pas un simple miroir ecclésiastique du monde esclave. Il constitue un indice parmi d'autres que des esclaves de la ville de Salvador, en ce début du XVIII ${ }^{\mathrm{e}}$ siècle, ont fait de la reconnaissance pleine et entière de leur statut de chrétien, un objectif ${ }^{88}$. Ce statut de chrétien passe par une possibilité d'accès au mariage. Il s'agit de la part des esclaves d'une incorporation du discours de l'Église, en vue de leurs propres intérêts, afin de pouvoir mieux résister à l'arbitraire de la domination seigneuriale et, de manière générale, afin de gagner un surcroît de dignité au sein de la société coloniale ${ }^{89}$.

86 - Arquivo da Cúria Metropolitana de São Paulo, 4-59-388 (1755) : Eliana GoldSCHMidT, «Matrimônio e escravidão em São Paulo colonial: dificuldades e solidaridades », in M. B. Nizza da Silva, Brasil colonização e escravidão, Rio de Janeiro, Nova Fronteira, 2000, p. $59-72$.

87 - A. J. R. RusselL-WoOD, «Black and mulatto brotherhoods... », art. cit., met en doute l'existence d'une telle conscience dans le Brésil du début du XVIII ${ }^{\mathrm{e}}$ siècle.

88 - La dévotion comme symbole d'identité des esclaves commence à être analysée. Pour le cas de Rio de Janeiro et des Minas Gerais, voir Anderson José Machado de OliveIra, Devoção negra: santos pretos e catequese no Brasil colonial, Rio de Janeiro, Quartet/ FAPERJ, 2008.

89 - On peut tenter ici un parallèle avec les Indiens dévots de la ville de Lima au $\mathrm{XVII}^{\mathrm{e}}$ siècle et l'ambivalence de l'institution ecclésiastique, locale mais aussi romaine, qui incorpore les Indiens tout en les maintenant dans un statut de mineurs sur le plan religieux, voir l'étude magistrale de Juan Carlos Estenssoro Fuchs, Del paganismo a la santidad. La incorporación de los Indios del Perú al Catolicismo 1532-1750, Lima, Instituto francês de Estudos Andinos, 2003, notamment le chap. 6. 


\section{La liberté du sacrement}

Les Constitutions de l'archevêché de Bahia promulguées en 1707 furent imprimées en 1719 à Lisbonne et s'appliquèrent pour l'Amérique portugaise jusqu'au XIX ${ }^{\mathrm{e}}$ siècle. Les canons sur le mariage des esclaves y affirmaient la liberté du sacrement du mariage. Selon l'archevêque de Bahia, citant dans ses notes Thomas d'Aquin : «pour contracter un mariage dans la foi de Jésus-Christ, c'est la même liberté pour les libres et pour les esclaves ", la liberté avait un sens précis, elle s'appliquait uniquement au sacrement et elle s'accommodait de l'esclavage. Les Constitutions n'offraient pas aux esclaves l'arme de l'excommunication pour lutter contre l'oppression de leurs maîtres. Le pape n'avait pas accédé à la demande des esclaves de Bahia malgré l'habile mise en scène de la parole des esclaves par le jésuite Brandolini.

Il est intéressant de rapprocher ces débats de droit canonique d'autres épisodes contemporains qui marquent, selon l'avis de plusieurs historiens, une forme de durcissement du système esclavagiste au moment où le Brésil fait face à la découverte de l'or et à l'accroissement de sa population servile. Le parallèle avec la législation civile est en effet éclairant. En 1698, sous la pression des maîtres d'esclaves appuyés par le gouverneur, Dom Pedro II avait retiré la possibilité accordée en 1688 aux esclaves de déposer contre leurs maîtres devant un tribunal en cas de châtiments excessifs. La législation contre les châtiments était du coup réduite à des recommandations de modération à l'attention des maîtres sans réelle possibilité de recours pour les esclaves. Dans leurs arguments, les adversaires de la législation avaient expliqué que les dépositions de plaintes d'esclaves contre leurs maîtres ouvraient une brèche dans le système de domination et entraînaient un désordre social. En effet, les esclaves avaient été nombreux à recourir contre leur maître devant le tribunal royal ${ }^{90}$.

De la même façon, Silvia Hunold Lara a montré comment la voie de la négociation avec les esclaves fugitifs du quilombo de Palmares a été abandonnée. Le traité de paix signé avec le roi Zumba en 1679, qui accordait la liberté aux hommes et aux femmes nés dans le quilombo, avait rapidement laissé place à l'option de la destruction militaire. Là encore, le traité était apparu comme dangereux pour le système esclavagiste car, de fait, il légitimait le quilombo, c'est-à-dire la fuite et la résistance comme voie d'accès à la liberté ${ }^{91}$.

Le droit canonique s'inscrit pour une part dans cette même logique de fermeture des sociétés esclavagistes. Les Constitutions de 1707 réaffirment le droit des esclaves à se marier en conformité avec la doctrine de l'Église universelle, mais elles n'offrent pas l'arme de l'excommunication aux esclaves pour se défendre contre leurs maîtres. De manière plus insidieuse, les Constitutions affirment qu'un esclave peut être un bon chrétien (baptisé, instruit et marié) mais qu'il reste esclave, soulignant ainsi que le christianisme n'est pas une voie de sortie de l'esclavage. Or, cette idée reste en débat à la fin du XVII ${ }^{\mathrm{e}}$ siècle. Si l'esclavage 
permettait de sortir du paganisme, pourquoi la totale christianisation ne libéreraitelle pas de l'esclavage? Les esclaves ou affranchis chrétiens, comme l'ambassadeur da Silva Mendonça, interrogent sur ce point la Curie romaine. Les cardinaux du Saint-Office et de la Propaganda Fide se contentent de condamner moralement les maîtres qui pratiquent des abus sur leurs esclaves, mais ils ne remettent pas en question l'esclavage perpétuel et transmissible à leur descendance des esclaves chrétiens ${ }^{92}$.

Par leur recul ou leur silence, les autorités civiles et ecclésiastiques affirment ainsi que l'unique moyen d'affranchissement dans la société esclavagiste est la décision du maître. En ce tournant du XVII ${ }^{\mathrm{e}}$ et du XVIII ${ }^{\mathrm{e}}$ siècle, on assiste ainsi à un durcissement de la législation esclavagiste qui contribue à expliquer que l'esclavage ait pu durer jusqu'en 1888 au Brésil. Malgré ses formules radicales, le droit canonique, en soulignant la compatibilité entre le christianisme et l'esclavage, a ainsi pu contribuer au maintien de l'esclavage dans cette société catholique.

Il n'en reste pas moins que la défense du mariage par les ecclésiastiques repose sur l'idée forte de la liberté du sacrement et de la dignité conférée par le mariage. Les Constitutions de 1707 développent ces thématiques que des ecclésiastiques, notamment des jésuites italiens, diffusèrent par le biais des sermons, des missions publiques et comme médiateurs auprès des confréries. Ceci explique que les esclaves aient pu adhérer au discours de l'Église et s'emparer de l'idée de liberté du sacrement pour leurs propres stratégies personnelles. Pour eux, jouir de la liberté du sacrement de mariage pouvait signifier dans certains cas une plus grande autonomie au sein du carcan de l'esclavage, une protection contre les séparations forcées, et une possibilité de reconstituer des réseaux, notamment pour les Africains. Le mariage chrétien représentait aussi un accomplissement de leur dévotion, l'accès à une forme de reconnaissance et une première étape vers la liberté, en assurant celle de leur descendance par l'union avec une femme libre. Le Mémorial des esclaves de 1708 représente ainsi une forme d'appropriation du discours de l'Église par des esclaves qui agissent à Bahia au début du XVIII siècle pour une plus grande autonomie et vers plus de liberté.

Charlotte de Castelnau-L'Estoile

Paris Ouest-CNRS-Mascipol

Universidade Federal Fluminense-Faperj (Rio de Janeiro, Brésil)

92 - H. MATtos, «A escravidão moderna... », art. cit. 